$3-2013$

\title{
Achievement Motivation and Study Strategies of Graduate Students: Testing Boundary Conditions of Theoretical Constructs
}

Kevin R. Francom

University of St. Augustine for Health Sciences

DOI: https://doi.org/10.46409/sr.WRDW9470

Follow this and additional works at: https://soar.usa.edu/dissertations

Part of the Educational Psychology Commons, and the Higher Education Commons

\section{Recommended Citation}

Francom, K. R. (2013). Achievement Motivation and Study Strategies of Graduate Students: Testing Boundary Conditions of Theoretical Constructs. [Doctoral project, University of St Augustine for Health Sciences].SOAR @ USA: Student Dissertations Collection. https://doi.org/10.46409/sr.WRDW9470

This Dissertation is brought to you for free and open access by the Student Research at SOAR @ USA. It has been accepted for inclusion in Student Dissertations by an authorized administrator of SOAR @ USA. For more information, please contact soar@usa.edu, erobinson@usa.edu. 
Achievement Motivation and Study Strategies of Graduate Students: Testing Boundary Conditions of Theoretical Constructs

Submitted to University of St Augustine for Health Sciences

in Partial Fulfillment of the

Requirements for the Degree of

DOCTOR OF EDUCATION

by

Kevin R. Francom

St. Augustine, Florida

March 2013 
Copyright Kevin Ronald Francom 2013

All Rights Reserved 
University of St. Augustine for Health Sciences Doctor of Education Department

We hereby approve the dissertation of

$$
\text { Kevin Ronald Francom }
$$

Candidate for the degree of Doctor of Education

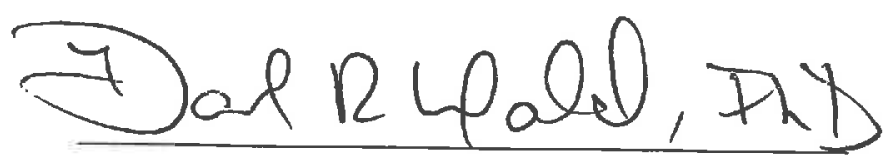

Committee Chairperson: Daniel R. Lofald, $\mathrm{PhD}$ Director/Associate Professor EdD/DHSc

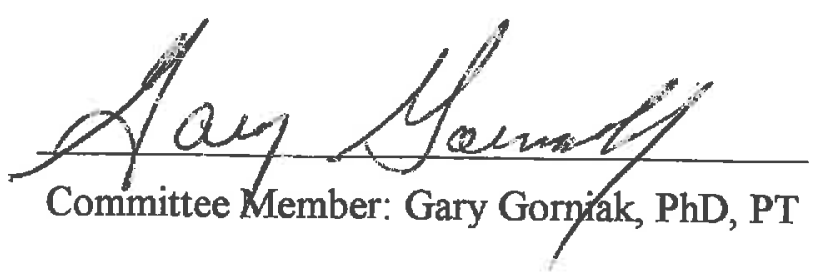

Gidy Mathena

Committee Member: Cindy Mathena, $\mathrm{PhD}, \mathrm{OTR} / \mathrm{L}$ VP/Dean of Post Professional Studies

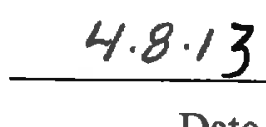




\begin{abstract}
Professional graduate student programs have relatively low completion rates, which comes at significant cost to the university and student. Achievement motivation theory can account for success or failure with undergraduate students, but this has not been fully tested with graduate students. This study found that achievement motivation theory was a modest predictor of student achievement and type of study strategy use for first-term graduate students at the University of St. Augustine. Certain achievement goal orientations and study strategy combinations may affect a graduate student's academic success. Achievement goal orientations, along with study strategies, may comprise helpful criteria to identify students most likely to succeed in graduate programs.
\end{abstract}




\section{Acknowledgement}

The challenge of completing this education degree with a dissertation has been one of the most difficult things I have encountered. Without the guidance, help, and patience of the foillowing people, I would never be writing this page. To these people I owe a debt of gratitude.

- Daniel Lofald, who kept trying to paint a picture that my eyes just could not see. His sense of humor pulled me along in the toughest hours. With his profound wisdom, extensive knowledge, and commitment to the highest standards, he helped make this dissertation what it is today.

- Gary Gorniak, who provided the means and the real-world perspective to allow this research to happen. Also, for his persistent expectation of excellence and guiding instruction.

- Cindy Mathena, who always shared an encouraging word. Her willingness to take the time to explain and guide, even when time was short, was invaluable.

- Family, mentioned last but not least, who not only stood by my side for the duration of this trial, but helped, encouraged, and buoyed me up throughout the entire process. 
Table of Contents

Abstract 2

Acknowledgement 3

Table of Contents 4

Chapter One: Introduction $\quad 7$

1.1 Attrition 7

$\begin{array}{ll}1.2 \text { Motivation theory } & 8\end{array}$

1.3 Historical backdrop 9

1.4 Achievement needs 12

1.5 Current state of achievement needs $\quad 14$

$\begin{array}{ll}1.6 \text { Study strategies } & 14\end{array}$

$\begin{array}{ll}1.7 \text { Summary } & 15\end{array}$

Statement of the Problem 16

1.8 Retention and attrition defined 16

$\begin{array}{ll}1.9 \text { Summary of problem } & 17\end{array}$

$\begin{array}{ll}\text { Purpose of the Study } & 18\end{array}$

$\begin{array}{ll}1.10 \text { Purpose introduction } & 18\end{array}$

1.11 Research questions 19

$\begin{array}{ll}1.12 \text { Hypotheses } & 19\end{array}$

1.13 Secondary hypotheses $\quad 21$

1.14 Organization of the remainder of the study 21

Chapter Two: Review of the Literature 22

2.1 What we know about undergraduate students 22

2.2 Comparing undergraduate to graduate studies 23

2.3 Significance of graduate students 23

2.4 Cost of attrition $\quad 24$

2.5 Motivation defined 26

2.6 Motivation theory background 28 
2.7 Transitioning from behaviorism to cognitive theory 30

2.8 Social-Cognitive theory $\quad 32$

2.9 Achievement motivation theoretical framework 34

2.10 Achievement goal orientation $\quad 39$

2.11 Factor analysis $\quad 42$

$2.122 \times 2$ Goal orientation framework $\quad 45$

2.13 Study strategies $\quad 48$

2.14 Achievement goals and study strategies 50

2.15 Achievement motivation theory may help explain success in school 54

2.16 Summary $\quad 56$

Chapter Three: Research Design and Methodology 57

3.1 Introduction $\quad 57$

3.2 Questions $\quad 58$

3.3 Hypotheses $\quad 58$

3.4 Secondary hypotheses $\quad 59$

3.5 Population and Sample $\quad 60$

$\begin{array}{ll}3.6 \text { Ethical considerations } & 60\end{array}$

3.7 Generalizability $\quad 61$

3.8 Data collection and instrumentation $\quad 62$

3.9 Research design and data analysis 64

3.10 Summary $\quad 66$

3.11 Limitations and delimitations $\quad 66$

Chapter Four: Analysis of Data $\quad 68$

4.1 Analysis of data $\quad 68$

$\begin{array}{ll}4.2 \text { Hypotheses } & 69\end{array}$

4.3 Secondary hypotheses $\quad 70$

4.4 Respondent demographics 71

4.5 Discipline comparison $\quad 73$

$\begin{array}{ll}\text { 4.6 Achievement goal factor inter-correlations } & 74\end{array}$ 
4.7 Achievement goal and study strategy factors 75

$\begin{array}{ll}4.8 \text { Perisistence } & 76\end{array}$

$\begin{array}{ll}4.9 \text { Examination scores } & 77\end{array}$

$\begin{array}{ll}4.10 \text { Summary } & 78\end{array}$

Chapter Five: Conclusions and Recommendations for Future Research $\quad 79$

$\begin{array}{ll}5.1 \text { Summary } & 79\end{array}$

$\begin{array}{ll}5.2 \text { Achievement and study strategies } & 81\end{array}$

5.3 Conclusions $\quad 82$

5.4 Faculty can affect retention $\quad 82$

5.5 Promoting study strategies $\quad 84$

5.6 Recommendations for future research 85

5.7 Qualitative research component $\quad 85$

5.8 Instrumentation suggestion $\quad 86$

$\begin{array}{ll}5.9 \text { Repeated measures design } & 87\end{array}$

$\begin{array}{ll}5.10 \text { Conclusion } & 87\end{array}$

$\begin{array}{ll}\text { References } & 88\end{array}$

$\begin{array}{ll}\text { Appendix A } & 99\end{array}$

$\begin{array}{ll}\text { Appendix B } & 101\end{array}$

$\begin{array}{ll}\text { Appendix C } & 103\end{array}$ 


\section{Chapter One}

\section{Introduction}

\subsection{Attrition}

The attrition rate seen in many graduate student programs is relatively high. As reported by the American College Testing (ACT) organization (2011), the rate of attrition in 2011 for public professional graduate degree programs was 61.4 percent, and for private graduate programs it was at 44.8 percent. The rates in 2011 were relatively similar to the 2006 rates of attrition at 62.1 percent for public degree programs and 43.9 percent for private degree programs (ACT, 2006).

Research has shown that pre-admission student performance data such as grades and standard aptitude testing are relatively helpful data for researchers and educators to predict the likelihood that a student may drop out of a program (Ramist, 1981); however these do not provide the entire picture. What is apparent, is that students in a professional graduate degree program who struggle academically are at high risk of leaving their college studies. Researchers approximate that sixty-five percent of graduate students who dropped out from a health professional program were due to academic reasons (Andrews, Johansson, Chinworth, \& Akroyd, 2006). More than half of the students who left the program dropped out due to failure to meet academic standards. What makes the Andrews, Johansson, Chinworth, \& Akroyd (2006) study unique is that it was completed for a physical therapy program and thus has particular relevance to the current study.

Universities often base methods to improve student's grade point averages on the assumption that an increased grade point average decreases the chance that the student 
will drop out (Lotkowski, Robbins, \& Noeth, 2004). Research has supported this

premise (Ishitani, 2002). One might conjecture that students who drop out lack the raw intellectual skills necessary to succeed. Yet it is also possible that many students who prematurely leave their studies have the intellectual gifts necessary, but lack the motivational dispositions that are essential to complete graduate school. This project will explore this possibility.

\subsection{Motivation theory}

Motivation theory, a sub-division of the field of educational psychology, helps researchers, practitioners, and educators develop a more complete understanding of why students do what they do. Motivation can affect how and what students learn (Schunk, 1996). When attempting to identify the motivational predictors underlying a student's action, four major indices are frequently used. These indices are task choice, effort, task persistence, and achievement.

These indices are crucial to the study of motivation because these define the parameters of the motivation attribute. When addressing the motivational dispositions of graduate students in a high-stakes, challenging examination environment, the index of task choice may apply to the type of study strategy use in preparation for the examination. However, task choice will not be a focus of this study at this time due to the fact that the graduate students involved in this study were not given an alternate choice to taking the examination. Effort, persistence, and achievement remain important indices of motivation for this study with graduate students in preparation for an examination. The index of effort can be measured when students apply varying levels of effort to a task. Persistence in the presence of obstacles can be a good indicator of student motivation and 
is highly correlated with those students who complete the program. Achievement is a combination of the previous three indices and, as such, is an indirect measure of motivation. These indices will be addressed in depth later in this manuscript.

\subsection{Historical backdrop}

Historically, there have been many different motivational theories used to explain human behavior. Two of these theories include drive and behavioral theories. Theorists who applied these theories generally described motivation as a change in human behavior as a consequence of environmental events or other stimuli. In its most basic form, motivation was initially explained as the consequence of a stimulus while cognition and thoughts of the individual were not addressed. Alternatively, contemporary theories of human motivation include expectancy-value, attribution, and social cognitive theories. The unifying common feature of these later theories are that these generally lead theorists to stress the importance of mental processes like beliefs, thoughts, and perceptions to produce behaviors, which are the products of motivation. These cognitive theories have guided the notion that motivation is an internal attribute typically characterized by a student's belief systems and consequently their actions (Atkinson, 1964). The specific cognitive motivation theory that will be used for the purposes of this project is the expectancy-value theory.

There are two basic beliefs that need to be understood when investigating the fundamental reasons behind why a student is motivated to perform a task. These beliefs are known as expectancy and value beliefs. An expectancy belief is what a student believes about their capability to succeed at a task. To illustrate an expectancy belief requires a simple self-question; can I do the task? The degree of importance or how 
relevant the student believes the task is to them is known as a value belief. The portrayal of a value belief comes from the self-question; do I want to do the task? The expectancyvalue theories of motivation include a student's hypotheses about the nature of the world and how the student can affect or be affected by the world (Atkinson, 1964). The exact nature of how these two variables work together can be complex. Therefore, the intricacies between these two variables will be discussed at greater length later in this paper.

Cognitive theorists generally agree on the importance of expectancy and value beliefs in understanding student motivation. However, there has been disagreement as to which mental processes are the most important in developing expectancies and values. Rotter (1966), who developed one of the earliest expectancy-value theories, postulated that a central motivational theory had to do with how humans deem causation in their own world. In his theory, he explains that the degree to which humans differ resides in terms of where they see the source of causation in their world (Rotter, 1966). The perception of the student about who is in control of their life ends up somewhere along a continuum from the point where the student is in control of events (an internal locus of control), to the world being in control of the events that affect the student (an external locus of control).

At one end of the internal/external locus of control continuum, or at one extreme, there are those students who exclusively describe the world as happening to them. Rotter (1966) coined these students 'pawns'. At the opposite extreme of the continuum are those students who take full responsibility and see themselves as happening to the world. Rotter (1966) coined those students 'stewards'. On their own motivational continuum, most 
students tend to operate near the middle between these two extremes of motivation. Students may migrate toward one side or the other depending on their changing expectancy or value beliefs (Rotter, 1990). Students with pawn orientations can be exceedingly difficult to work with as they fail to take responsibility for their own behavior. In modern theories of human motivation it appears that theories not only attempt to account for motivational constructs in terms of the internal mental events of the student, but the constructs also frequently have to do with student perceptions about causation.

Another expectancy-value theory of motivation was developed by Atkinson (1966) and is known as the achievement motivation theory. Both locus of control and achievement motivation theories help to explain a range of student behavior that depends on beliefs and needs, respectively. Atkinson described behavior as a result of a student's need for achievement as well as a need to avoid failure. Up until that time, the focus was on various levels of the need for achievement. Because achievement motivation theory was specific to learning situations (Aikinson, 1964), it fit well with motivation in an educational setting. Achievement motivation theory was then used to describe the motivational processes that affected the success of students on cognitive tasks (Wolters, 2004).

While Atkinson's theory of achievement motivation may appear similar in style to Rotter's (1966) internal/external locus of control continuum, the achievement motivation theory explains that students differ in terms of needs that they attempt to satisfy in learning situations. On one extreme of the achievement motivation continuum are students who have a perceived need for mastery. The mastery oriented student works 
towards satisfying his or her personal learning needs. In this respect, Atkinson (1966) posited that these students are motivated by things other than outwardly-oriented definitions of success like grades or praise from teachers. At the other extreme end of the continuum are students who are principally motivated to avoid failure. These students are excessively concerned about how peers and instructors view their performance. These students see their world through the eyes of others.

\subsection{Achievement needs}

Achievement needs develop as a result of the student's experiences in the world. While there is evidence that these needs can change in different learning contexts, it is also true that the achievement needs are generally stable (Harackiewicz, Barron, Tauer, \& Elliot, 2002). Considered over the entire educational history of a person, achievement needs are important. Early work by Diener \& Dweck (1978) identified two behavioral response patterns when students were faced with challenging tasks. The first pattern was identified as a helpless, or maladaptive, response pattern. Students showing a helpless behavioral pattern would normally avoid challenging tasks as well as demonstrate a decreased performance level when challenged. These students tended to avoid intellectual risks and were at a greater risk of not pursuing lifelong learning opportunities after leaving the school environment. A second behavioral pattern, also described as an adaptive response, was identified as a mastery-oriented response. Mastery-oriented students would seek out challenges and demonstrate increased effort even when failure was imminent (Diener \& Dweck, 1978). These students tended to be intellectual risktakers and did well with the motivational indexes of choice, task persistence, effort, and hence, achievement. In an effort to describe the adaptive or maladaptive responses to 
challenges, Dweck and Elliot (1983) explored the goals that students were pursuing in learning environments, such as school. This research organized student responses into a mastery or performance type of goal. Additional research identified why students gravitate towards using a performance or a mastery goal in a particular situation (Elliot \& Dweck, 1988; Nicholls, 1975). These studies suggest that what makes achievement needs important is how these needs are concomitantly related to other intellectual variables, such as study strategies. These additional variables will be outlined shortly. The next significant advancement in achievement motivation theory was described by Elliot and Harackiewicz (1996). They suggested that the 'performance orientation' construct needed to be further divided into two separate factors.

The function of factor analysis is to discover latent variables that explain the most amount of variance in the dependent variable. Harackiewicz, Barron, Pintrich, Elliot, \& Thrash (2002) established that a better factor analytic solution than the singular 'performance' orientation could be offered by splitting it into 'Performance-Approach Goals' and 'Performance-Avoidance Goals.' The performance-approach orientation is adopted by students desiring to attain success and receive the highest grade relative to others. The performance-avoidance orientation is adopted by students who attempt to avoid failure and not be considered incompetent, which would be evidenced by a poor grade (Murayama, Elliot, \& Yamagata, 2011). The motivation to perform relative to others remains strong whether students adopt a performance-approach or a performanceavoidance goal orientation. Therefore, in 2002 , the best factor analytic solution included three latent variables identified as mastery, performance-approach, and performanceavoidance orientations (Harackiewicz, Barron, Pintrich, Elliot, \& Thrash, 2002). 


\subsection{Current state of achievement needs}

In an attempt to further test the three factor solution within motivated behavior, Zweig and Webster (2004) authenticated the reliability and validity of the three-factor structure used today and is the instrument used in this current study. It is called the Goal Orientation Measure (Zweig \& Webster, 2004). This measure contains a total of twentyone items with three scales containing seven items each. It was administered here as a paper and pencil instrument and will be explained in detail in chapter three.

What makes achievement needs important is how these needs are concomitantly related to other intellectual variables, such as study strategies. Previous studies have demonstrated a link between a student's achievement goal orientation and study strategies (Crede \& Kuncel, 2008; Simmons, Dewitte, \& Lens, 2004). It appears that when students use a certain type of achievement goal orientation, they typically use a certain type of study strategy. What remains uncertain presently is the direction of causality between achievement goal orientation and study strategies. Simply, does one cause the other? Causai directions are not the focus of the present study, but may be a valid question for future research. This project will assess how well achievement goal theory holds for a specific graduate student population in a high-stakes examination scenario.

\subsection{Study strategies}

A study strategy is a guideline composed of study tactics that the student has found to be most effective for their learning (Gettinger \& Seibert, 2002). A study strategy may include the cognitive processes a student uses during a lecture to understand how different topics pertain to each other. An example of a deep-processing study strategy 
includes a student questioning the validity of the information presented in a lecture and then attempting to organize the information with their previous knowledge (Elliot, McGregor, \& Gable, 1999). Another study strategy example may involve reading the text and class notes and memorizing definitions. This would be an illustration of a surfaceprocessing study strategy, which involves repetitive rehearsal of information (Elliot, McGregor, \& Gable, 1999). Using an effective study strategy that promotes deepprocessing levels is one factor that may help explain successful academic performance (Craik \& Lockhart, 1972). Effective study strategies and academic achievement goals have been listed as two of the best overall predictors of undergraduate student retention (Crede \& Kuncel, 2008; Robbins, Lauver, Le, Davis, Langley, \& Carlstrom, 2004). In the current project, study strategies were operationalized using the Cognitive/Metacognitive Study Strategy questionnaire. This instrument consisted of nineteen questions in four distinct categories and will be discussed in more detail in chapter three.

\subsection{Summary}

It is estimated that fifty percent of doctoral graduate students in the United States do not obtain the degree (Lovitts, 2001). There are potentially many factors at work that cause graduate students to drop out from their programs. Research on graduate retention is lagging behind what is known about undergraduate retention. What is known is that the variables at work with undergraduate students may not necessarily have high explanatory power with graduate populations (Girves \& Wemmerus, 1988; Golde, 2005). Looking at the achievement goal orientations for graduate students and matching them with their study strategies may help to explain some of the variables that contribute to graduate student retention (Elliot, McGregor, \& Gable, 1999). With this information, an 
educational institution might better refine the targeted profile of its prospective students.

It is also conceivable that intervention strategies might be used to ameliorate

dysfunctional achievement motivations and surface level study strategies, which may help improve retention.

\section{Statement of the Problem}

\subsection{Retention and attrition defined}

Students in high-cost professional doctoral programs have relatively low program completion rates (ACT, 2011). The words retention and attrition are typically used to address student drop out from educational programs and have almost opposite meanings. Retention refers to the students who make it to graduation while attrition refers to those students who prematurely leave their studies. For the purposes of this project, graduate student retention will be referred to as the percent of graduates who complete their degree within 150 percent of the standard time allotted by the school. Attrition of graduate students will be operationalized as the percent of students who do not complete their degree within 150 percent of the standard time allotted by the school (ACT, 2011). It is important to note that students may eventually graduate, but if they have taken longer than 150 percent of the time, they are included in the attrition category.

The ACT Institutional Data File (2011) contains a report showing that public Masters $/ 1^{\text {st }}$ professional degree programs in the United States had a 61.4 percent attrition rate and private Masters $/ 1^{\text {st }}$ professional degree programs in the United States had a 44.8 percent attrition rate in 2011. According to these recent figures, a graduate university could anticipate losing about half of its student cohort before their expected graduation. This has not been a problem isolated to one year, as the numbers from the year 2000 to 
2011 were relatively constant. The rates of attrition in 2000 were at 63 percent for public professional degree programs and 45.3 percent in private professional degree programs (ACT, 2000).

In addition to the hard numbers that represent attrition rates, there are other reasons why graduate student attrition is important. The Council of Graduate Schools asserts that:

Attrition in U.S. graduate programs is a tremendous waste of American's financial resources and human energies. Increasing demand for workers with advanced training at the graduate level, an inadequate domestic talent pool, and a small representation of women and minority graduates at all education levels are among some growing concerns over workforce issues that relate to the vitality and competitiveness of the U.S. economy. Improving completion rates for all doctoral students, and particularly for those from underrepresented groups, is vital to meeting our nation's present and future workforce needs. (Council of Graduate Schools, 2012)

\subsection{Summary of problem}

There are potentially many factors that contribute to a graduate student's decision to drop out from their program. There has been extensive research performed with undergraduate students that has shown promising explanations for why students drop out along with solutions that address the problem of attrition. It is not known if these same explanations and solutions pertain to professional doctorate graduate students. 


\section{Purpose of the Study}

\subsection{Purpose introduction}

Different types of achievement goal use have been shown to predict different study strategy use by undergraduate students (Elliot, McGregor, \& Gable, 1999). The undergraduate students who chiefly use a mastery goal orientation also tend to employ the use of deep-processing study skills, persistence, and sufficient effort required to learn. Undergraduate students using a performance goal orientation will typically use strategies such as surface-processing and disorganization. What remains unclear at this time is whether specific achievement goal types will predict study strategy methods used by graduate students to prepare for an examination.

The purpose of this study is to collect data to investigate the relationships between achievement goal motivation, student study strategy factors and actual outcomes on a high-stakes graduate student anatomy examination in a face-to-face traditional classroom setting. Two factors make the present study unique. First, the retention rate for the program under investigation in this study is higher than ninety-five percent. This program only reports the on-time graduation rate, which is defined as the students who compete their program within 100 percent of the scheduled program length. The second factor is that the researcher collected data from students taking their first anatomy course in graduate school. Students and faculty from the University of St. Augustine are of the general agreement that this is potentially the most difficult course in terms of subject material taken by the physical and occupational therapy students for whom it is required. The data was collected both immediately before and after the second of four examinations in this course. The second examination was used, rather than the first of the 
course, to allow the students to experience the testing method and question types used for this course. Again, this particular examination is considered a leading indicator of students who tend to go forward successfully and those who may need to go to part-time status or otherwise may have difficulty moving forward. The ultimate retention of these students will be reported in a later study. However, the reader can clearly discern that the purpose of the present project is not to pursue high generalizability to other populations or even possibly to other courses. Since there is such a paucity of theoretically grounded research on professional graduate student retention, the goal in the present study is to test the boundary conditions of both academic achievement needs and study strategies under highly demanding circumstances. The question to be answered is to find out if these variables have any prediction power, even under these most extreme conditions.

\subsection{Research questions}

1. Does performance on the Goal Orientation Measure instrument of achievement motivation explain variance in examination performance for first-term graduate students at the University of St. Augustine?

2. Does performance on the Goal Orientation Measure instrument of achievement motivation explain variance in the type of study strategies used by first-term graduate students at the University of St. Augustine to prepare for an examination?

\subsection{Hypotheses}

1. There is a statistically significant and positive correlation between measures on the mastery goal factor and the performance-approach goal factor. 
2. There is a statistically significant and negative correlation between measures on the mastery goal factor and the performance-avoidance goal factor.

3. There is a statistically significant and positive correlation between student reports of a mastery goal factor and a deep-processing study strategy factor.

4. There is a statistically significant and positive correlation between student reports of a performance-approach goal factor and a deep-processing study strategy factor.

5. There is a statistically significant and positive correlation between student reports of a performance-avoidance goal factor and a surface-processing study strategy factor.

6. There is a statistically significant and positive correlation between student reports of a performance-avoidance goal factor and a disorganized studying strategy factor.

7. There is a statistically significant and positive correlation between student reports of persistence in studying and a mastery goal factor.

8. There is a statistically significant and positive correlation between student reports of persistence in studying and a deep-processing study strategy factor.

9. There is a negative and statistically significant correlation between examination scores and measures on the performance-avoidance goal factor.

10. There is a negative and statistically significant correlation between examination scores and student reports of a disorganized studying strategy factor. 


\subsection{Secondary hypotheses}

1. There is not a statistically significant comparison between the means of gender and examination score.

2. There is not a statistically significant comparison between the means of gender and discipline.

3. There is not a statistically significant comparison between the means of discipline and examination score.

\subsection{Organization of the remainder of the study}

Chapter one outlined the problem and the purpose of the current study. It also laid the foundation for the literature review in Chapter two, which synthesizes and critiques the research to set the framework for the issues and variables under investigation. Chapter three describes the issues and variables in concrete procedures used to answer the research question. It also consists of the rationale and appropriateness of the data collection procedures. Chapter three reviews the instruments used to gather the data, as well as the statistical procedures used to test the hypothesis to answer the research question. Chapter four comprises the results of the statistical analysis using correlational based analyses to identify the relationship between goal orientation and study strategies to help predict graduate students academic success. Lastly, Chapter five offers the summary, conclusions, and recommendations for future research. 


\section{Chapter Two}

\section{Review of the Literature}

\subsection{What we know about undergraduate students}

The problem, as identified in chapter one, is that professional graduate student programs have relatively low completion rates, which comes at significant cost to the university and student alike. Most of the resources available to address retention in large university degree programs have been dedicated to the undergraduate student population (Pontius \& Harper, 2006). For instance, Tinto (2006) developed a model of student departure to explain that undergraduate students entered college with individual scholarly attributes as well as personal schooling commitments, such as staying at college, graduating from college, and getting good grades. These students also have commitments outside of school such as work and family that also can impact their decision to persist. Tinto (2006) hypothesized that academic and social integration work together to influence a student's collegiate goals and commitments, which may lead to his or her decision to remain enrolled or leave college. In his work with undergraduate students, Tinto (2006) found that academic and social engagement is critical to retention, especially during the first year of college. He also found that actions of the faculty, specifically in the classroom, are key to increasing student retention (Tinto, 2006). For example, one intervention he used involved instructors who challenged each student's assumption about their knowledge being internalized as well as helping the student take ownership over the learning process (Tinto, 1997). 


\subsection{Comparing undergraduate to graduate studies}

In spite of continued study, researchers continue to struggle identifying the factors that cause undergraduate students to drop out of school. In comparison to undergraduate studies, it is hypothesized that graduate student education, especially at the doctoral level, is typically less structured and more individualized than undergraduate studies, which may add to the challenges of attrition research (Isaac, 1993). One factor that may explain the relative lack of success in attrition research is that most studies have focused on student causes for leaving graduate studies rather than looking at departmental, faculty, or university causes (Golde, 2005).

\subsection{Significance of graduate students}

Graduate student attrition rates bear significance for at least three reasons (Baird, 1993). First, graduate students represent approximately one out of every four students enrolled in universities in the United States. Second, the students who graduate with advanced degrees from universities are those who will be the next engineers, administrators, researchers, health professionals, teachers, and managers in our society. Third, the cost for graduate students, and for the universities they attend, is quite high due to expensive facilities, small class sizes, and a smaller teacher to student ratio (Baird, 1993). In addition to the reasons stated above, studying graduate students is important because about half of the students enrolled in programs throughout the United States do not graduate. This number has remained fairly constant since at least the 1960s (Lovitts, 2001). Rummel, Action, Costello, and Pielow (1999) did explain that for a particular university program, forty-four percent of graduate students who left fell below the university's grade point average standard, which was set at a grade point average (GPA) 
of 2.0 or below. The belief that an improved grade point average will increase the likelihood of student retention has led to methods used by undergraduate education programs to improve grades, such as supplemental instruction (ACT, 2004). According to Andrews, Johansson, Chinworth, \& Akroyd (2006), the majority of attrition for physical therapy, nursing, and medical students is due to academic difficulty. However, even though grades have been associated with student attrition, it may be that the students were doing poorly due to lack of effective instruction on the variables of attainment, intrinsic motivation, and utility value (Eccles \& Wigfield, 2002).

As mentioned previously, graduate student attrition remains a persistent problem. If pre-admission measures such as prior grade point average, Graduate Record Examinations (GRE), essays, and interviews were effective at predicting good graduate student candidates for professional education, the expectation is that the attrition rate would be lower. However, because attrition rates remain high, it is possible that these cognitive measures are not fully sufficient explanatory devices for the problem of attrition. In this study, examination score will serve as a proxy measure to retention. Even though retention would be the ultimate dependent measure, it is not the chosen purpose for this project, but will be considered for a follow-up study.

\subsection{Cost of attrition}

Attrition in graduate education can be costly for the institution as well as for the student. The University of Notre Dame found that it could save $\$ 1$ million per year in stipends alone if doctoral student attrition decreased by $10 \%$ (Smallwood, 2004). Because many institutional costs are fixed, such as with equipment and facilities, the loss of each student translates into higher operating costs for each remaining student. The economic 
cost of attrition in graduate studies increases for the university if students drop out later in the program (Golde, 2005), which leads to institutional inefficiency (Baird, 1993); figuratively speaking, a seat remains empty with no concomitant decrease in fixed costs. For graduate students, the financial cost of failure in college can be significant (Chatterjee \& Ionescu, 2012). Students who assume a loan for an education that they do not complete may not ever achieve the earning capacity to repay the lender (Chatterjee \& Ionescu, 2012). Student default on loans continues to be a problem, whether the students drop out of school or not. In the fiscal year 2009, the undergraduate student cohort consisted of borrowers whose first loan repayments came due between October 1, 2008, and September 30,2009, and who defaulted in less than one year. In that time, more than 3.6 million borrowers from 5,900 schools entered repayment, and more than 320,000 students defaulted (U.S. Department of Education, 2011).

Even society as a whole can be adversely affected by attrition in graduate programs, particularly when it involves healthcare. For example, in 2010 there was a shortage of 19,000 physical therapists to handle patient demand within the United States (American Physical Therapy Association, 2012). This shortage is expected to increase even further through the year 2020. Along with monetary and societal costs, there are other intangible costs associated with attrition, including student life disruption (Gardner, 2008). This life disruption can present as an emotional cost to graduate student attrition, which centers mainly on difficulty coping after having failed at graduate studies (Gardner, 2008). Even though the actual causes of attrition may be varied, the underlying issue is that motivational constructs remain an unknown variable in the study of graduate student attrition. 


\subsection{Motivation defined}

"Motivation is the process whereby goal-directed activity is instigated and sustained" (Schunk, Pintrich, \& Meece, 2008, pg 4). The preceding definition of motivation outlines it as a process rather than an end product. As a process, motivation is not something that can be seen. Therefore, to measure motivation, it is inferred from a student's actions. These actions, also known as indices of motivation, are choice of tasks, effort, persistence, and achievement.

The first motivational index is choice of tasks. When a student has a choice between two learning tasks, the option he or she eventually chooses may indicate which task is more motivating. For example, students may be given a choice between presenting an oral report on the history of music and performing musical pieces that represent different eras of musical history. Task choice was an exceedingly important dependent measure in the 1990's when it was discovered that female college students were selfselecting out of the math and science courses that would eventually be necessary for them to enter science, technology, engineering, and math majors (Jones, 2002). Efforts at helping students from self-selecting out of productive majors are still underway (Harackiewicz, Rozek, Hulleman, \& Hyde, 2012). However, choice of tasks is not the most useful index of motivation in graduate programs where students are pursuing a professional, versus an academic, doctoral degree. For purposes of this project, graduate students in professional programs are not generally offered much in the way of electives and, for that reason, task choice will not be a variable that is investigated here.

The second index, effort, is an indicator of how motivated a student might be. Students who are motivated to learn will apply increased levels of effort to succeed. A 
high level of effort, especially on challenging tasks, may indicate that a student has an increased motivation to learn. A student motivated to learn may demonstrate habits such as organizing and rehearsing information, monitoring his or her level of comprehension, and relating new learning to previous experiences. The amount of effort used by a student to learn may vary depending on the student's skill level or previous experience with the topic. As a student's skill level increases, he or she may be able to perform better with less effort. If a student is proficient at an assigned task, he or she typically requires less effort to accomplish the goal and could initially appear to be less motivated. However, as a general rule, the level of effort invested can be used as a proxy measure of how motivated the individual is in performing the task.

The third motivational index is persistence, or time spent on a challenging task. Motivated students are more likely to persist in the presence of obstacles. Students who demonstrate a high motivational index of persistence may experience improved learning and accomplish greater tasks. In contemporary research, this motivational index finds its full expression in the study of student retention. Empirical investigations into student retention have helped researchers identify variables associated with persistence (Davidson, Beck, \& Milligan, 2009); however, as also mentioned above, much remains to be understood. The factors leading to student attrition vary from campus to campus and may even change over time on the same campus. Developing instructional interventions that help students increase their level of persistence is a common goal in academic environments. Therefore, colleges and universities are increasingly looking to the literature on persistence to guide their retention efforts (Davidson, Beck, \& Milligan, 2009). 
Achievement, the final index of motivation discussed here, is a combination of all the other indices and, as such, is an indirect measure of motivation. The achievement measurement is a product of the collective effects from the variables of persistence, choice, and effort. Students who choose to participate in a learning task, expend effort, and persist until the task is completed may achieve greater success. For example, a student who chooses to learn to play a new musical piece would find time to practice and would continue to practice even though the piece is challenging. Achievement, as an index of motivation, has been shown to be correlated with choice of tasks, effort, and persistence, which are the other three motivational indices (Pintrich, 2003).

\subsection{Motivation theory background}

Human motivation is an age-old question that dates back at least to the writings of the early Greeks. Even then, theories about what motivated humans varied dramatically. The Hedonists viewed the world through the over-simplified framework of the pursuit of pleasure and the escape of pain. At the other extreme, the thinking of Plato (Zeyl, 1980) saw motivation as the natural consequence of correct thinking that leads to Arete, or virtue. From these early concepts of human motivation came theories that focused on the driving forces that were thought to determine human behavior.

Drive theories were accepted during the first half of the twentieth century by theorists who emphasized that human behavior was directed by factors such as basic needs or instinct. As one can discern, these theories are merely a recapitulation of the pleasure and pain principles discussed by the Hedonists. These theorists used what ultimately became drive theories to explain behavior that helped a person maintain equilibrium, or balance, in his or her physical body (Woodworth, 1918). Continuing with 
drive theory, Hull (1943) developed three variables that explained the relationship between the drive and its effect on resultant behavior. These variables were identified as the intensity of the drive, the direction of the drive, and the amount of persistence the individual demonstrated in attaining the goal. The intensity variable in drive theory is the extent to which a drive activates behavior. Intensity of a drive can vary on a scale from too low to activate purposeful behavior to the opposite extreme of high intensity that instigates action (Hull, 1943). For example, a teacher presents new material in a class and encourages the students in the class to study. If a student knows there will be no test on the material, he or she may not study. On the other hand, if a student knows that the new material being presented will soon show up on a test that will determine his or her grade for the course, the student's drive to study would increase.

In the second half of the twentieth century, the work of Freud included drive theories and instincts as well. He posited that forces within the individual accounted for the individual's behavior. For him, the instinctual, driving force was his construct known as 'the id', which was sublimated or brought into equilibration, by the ego and super ego (Freud, 1966). For Freud, an id that was successfully sublimated to socially acceptable ends was deemed healthy. He gets credit for moving the source of motivation inside of the person, unlike the behaviorists; however, these were described as unconscious or subconscious choices, which are not that useful for the average busy classroom instructor.

Within Hull's (1943) drive theory, direction is identified by the object or goal of the drive. When a drive is initiated, the specific behavior that is used to satisfy the need is identified as the direction. For example, a student's drive to achieve a good grade leads him or her to study rather than go to sleep. The final variable pertaining to Hull's (1943) 
drive theory is persistence. Persistence in drive theory is known as the continuation of the behavior until the goal is achieved. Once the goal is achieved and the resultant need is satisfied, the drive that motivated the person to action is reduced and balance is restored again. Similar to behavioral explanations from drive theory, behavior theorists have used physical responses to stimuli to guide their definition of human motivation, which will be discussed next.

Behavioral theories were widely popular from early to the middle of the twentieth century. Behavioral theorists focused on the changes of behavior that came about due to different environmental or situational cues. Therefore, these theorists attempted to account for motivation in terms of observable actions. To illustrate, rewarding consequences of a behavior may lead a behavioral theorist to predict increased motivation and that the behavior might be repeated (Skinner, 1953). Likewise, punishing the consequence of a behavior may decrease motivation and make the behavior less likely to occur.

\subsection{Transitioning from behaviorism to cognitive theory}

Ultimately, behaviorism, and its focus on 'carrots and sticks,' failed as both a learning and a motivational theory (Pintrich, 2003). Behaviorists posited that environmental stimuli would give rise to specific and predictable responses. However, the lack of attention that was given to memory, motivation, and thinking to describe motivation within behavior theory caused a shift in thinking towards cognitive theory (Ally, 2008). It became apparent that the feelings, belief systems, and internal mental processes of humans were a much more powerful predictor of motivational ends than instinctual or environmental stimuli on their own (Bandura, 1975). 
In contrast to drive and behavioral theories, cognitive theories account for human thoughts, values, and aspirations (Lewin, 1935). Human motivation described by cognitive theorists is seen as driven by an individual's goals, personal interest, and choice. Each of these attributes plays a role in understanding human behavior. Cognitive theories of motivation focus specifically on understanding why people take part in activities for their own sake rather than out of an environmental dictate.

Cognitive theories such as attribution theory (Weiner, 1992), social cognitive theory (Bandura, 1986) and expectancy-value theories (Atkinson, 1958; Lewin, 1935) have continued to inform the question of human behavior. Attribution theory is based on the belief that students are conscious and rational in their decision-making processes (Weiner, 1992). When students speak about the reason that he or she has succeeded or failed at some task, he or she will invariably attribute the source of his or her success or failure to one or more causes. These causes are ability, effort, luck, and task difficulty. Intervention in attribution theory is directed towards changing the student's perception of causation. Consider this scenario: a student receives an 'A' grade on a paper and the teacher comments to the student that he is smart. Now the student will attribute getting an ' $A$ ' grade with being smart. If that same student later fails on a different paper, he may now attribute the failure to not being smart. In another scenario, the teacher comments to the student that he got an ' $A$ ' grade on his paper because he worked hard on his writing. If that same student later receives a poor grade on a different paper, he will attribute the poor grade to not working hard enough. In the second scenario, the teacher helped the student attribute the outcome to the amount of effort he used. The student now realizes that outcomes are not due to levels of intelligence, but rather due to amount of effort that 
was put forth. Having a fixed view of intelligence results in less than functional ends for students as will be discussed later in this manuscript. Understanding how a student attributes his or her successes or failures is highly predictive of his or her future behavior. Because the purposes of this study are to test the boundary limits of achievement motivation theory, attribution theory will not be used for this study.

\subsection{Social-Cognitive theory}

Another cognitive theory, known as the social-cognitive theory, posits that human achievement depends on interactions between a person's behaviors, personal factors, and the current environment (Schunk \& Pajares, 2002). In social-cognitive theory, what students think and feel, affects how they behave (Bandura, 1997). This is the foundation of Bandura's (1986) conception of what he termed reciprocal determinism. Reciprocal determinism is the view that an individual's internal feelings and cognitions, along with his or her behavioral and environmental influences, interact with each other that result in motivational consequences (Pajares, 2002). In the classroom setting, the cognitive, behavioral, and environmental factors influence each other in a reciprocal form. For example, a teacher presents a lesson and the students reflect on the topic: here the environment is influencing cognition. A student raises his hand to ask a question: here cognition is influencing behavior. The teacher reviews the content area addressing the question that was asked: here behavior is influencing the environment. Then the teacher questions the class to assess understanding: here the environment is influencing cognition. As these three factors interact with each other, a student's cognitions, environment, and behavior may positively affect learning (Bandura, 1997). In addition, social-cognitive theory explains the origins of mastery goal orientations (Dweck \& 
Leggett, 1988). While these interventions have proven successful with younger student populations, classroom interventions based on this theory may be less applicable with the professional graduate student population when compared to the expectancy-value theory.

The final cognitive theory included in this section is the expectancy-value theory, which is the theory chosen to be used for this study. Expectancy-value theorists (Atkinson, 1964; Wigfield, 1994; Rotter, 1966) explain that student behavior results from the expectation of the outcome as well as the value the student places on a task, which are the two most important predictors of achievement in the academic setting (Pintrich, 2003). For example, if a student expects to succeed and the value he or she places on the task is high, it is likely the student will participate in the task. If a student does not expect success in performing a task and does not value that task, it is likely that the student will not participate. Currently, the expectancy-value theory demonstrates that perceptions of the importance of a task, utility of a task, and interest in a task are the best predictors of the intentions for students to persist in academic settings (Wigfield \& Eccles, 1992).

One expectancy-value theorist, Rotter (1966), attempted to explain student behavior by referring to the student's belief, or perception, of how events in life are controlled. He named this belief a locus of control. Locus of control refers to a person's tendency to connect the results of their actions to an outcome. Students with an internal locus of control believe that they are in control of their situation (Rotter, 1966). For example, individuals with a high internal locus of control who do not perform well on a test would attribute the poor performance to lack of preparedness on their part. If the same student had performed well on the test, he or she would attribute the surcese tn hic or her ability to study. 
On the other hand, a student with an external locus of control believes that events in his or her life are controlled by environmental factors, which he or she perceives that cannot be influenced (Rotter, 1966). For example, if a student with a high external locus of control does poorly on a test, they might attribute their difficulty to the test questions being unfair. If they performed well on a test, they might think that the test was easy or that they were lucky. Students who have an extreme external locus of control do not assume responsibility for their behavior and may be a challenge in any classroom.

Another expectancy-value theorist, Atkinson (1964), described behavior as a result of a student's need for achievement. While achievement theory contains a few characteristics similar to Rotter's (1966) theory of locus of control, it does offer increased detail about students in an educational context. A detailed explanation of Atkinson's achievement motivation theory continues below.

\subsection{Achievement motivation theoretical framework}

Atkinson (1958) outlined a set of motivational indices and demonstrated the relation between them as a simple mathematical equation. The indices as he described included the tendency to achieve success (Ts) as being a product of the motive for success (Ms) multiplied by the probability for success (Ps) as well as the incentive value of the success (Is). Seen mathematically, the equation would appear: Ts = Ms x Ps x Is. If a student highly valued an upcoming test (Is) and believed that he or she would be successful in taking the test (Ps), and knew that a good grade on the test would bolster his or her grade for the class (Ms), then the student would have a high tendency to achieve success (Ts). Along with the high tendency to achieve success, the student would also be dedicated to effective preparation for the examination (Atkinson \& Feather, 1966). As 
one can see, there is an overlap of ideas between Atkinson's early work and the later work of Wigfield and Eccles (1992) already explained in this manuscript.

The first component that Atkinson (1958) described in the achievement motivation framework was the motive for success. Motives are seen in the world as the reasons why people act. In this framework, the actual motive by itself is not enough to explain why students act, so it is taken into account with an outcome expectation. In other words, a student's expectation of a positive or negative outcome may influence his or her decision to participate in an activity. For example, a student is likely to seek out and participate in achievement tasks when his or her motive, or expectation, for success is high. On the other hand, when the motive to avoid failure is high, the student is likely to avoid pursuing the task to avoid the embarrassment of failure (Atkinson, 1964).

All persons have the capacity for a motive to approach success as well as the capacity for a motive to avoid failure (Atkinson \& Raynor, 1974). This dichotomy of motives held by one individual becomes clearer when viewed in a model form as suggested by Covington \& Omelich (1991). If the motive to approach success and the motive to avoid failure are considered independent, then a $2 \times 2$ matrix can be created to describe four different approaches to achievement (See Figure 2-1). The four approaches are: success-oriented students, failure avoiders, overstrivers, and failure accepters. This model demonstrates how different students frame their achievement needs and how they attempt to meet those needs. For the purposes of this project, the two most useful approaches are the success-oriented student and the failure avoiders. 
Figure 2-1

Quadripolar model

Motive to approach success

\begin{tabular}{c|l|l|l|}
\cline { 3 - 4 } \multicolumn{1}{c|}{$\begin{array}{c}\text { Motive } \\
\text { to } \\
\text { to } \\
\text { avoid } \\
\text { failure }\end{array}$} & Low & $\begin{array}{l}\text { Failure } \\
\text { acceptors }\end{array}$ & $\begin{array}{l}\text { Success- } \\
\text { oriented } \\
\text { students }\end{array}$ \\
\cline { 3 - 4 } & High & $\begin{array}{l}\text { Failure } \\
\text { avoiders }\end{array}$ & Overstrivers \\
\cline { 3 - 4 } & & &
\end{tabular}

Covington (1999) gives a fairly comprehensive description of the success-

oriented and failure avoider student and how each student approaches a learning task. $\mathrm{He}$ describes the success-oriented student as having a high motive for success and a low fear of failure. The success-oriented students are generally optimistic and engage in learning activities. These students do not typically worry about performing well as far as grades are concerned. The failure avoider students are fearful of failing and are not motivated to succeed. These students are anxious and hold doubts about their ability to achieve success. They attempt to avoid failure by procrastinating and they use disorganized study strategies (Covington, 1999). This quadripolar model was a parallel development to the achievement motivation work previously done by Atkinson (1964). In his achievement motivation theory, Atkinson (1964) included two additional components into the achievement motivation theory that account for environmental factors in achievement settings, which are the probability for success and the incentive value of success. 
The second component included in Atkinson's achievement motivation framework is the probability for success. Probability for success is a student's belief of the likelihood they have of succeeding at a task. With the perception of the task as being easy, the higher the probability is for success. If the student perceives the task as being more difficult, his or her perception of the probability of success decreases. Similar to a student's own belief of ability, the probability for success relates to the difficulty of the task. The perceived challenges from the local environment in which the task is completed may change the student's perception of the probability for success (Atkinson, 1964). Using a ring-toss game with sophomore and junior year college-age males, Atkinson and Feather (1966) observed that when a student stood within one foot of the goal, his perceived probability of success was at 100 percent. When standing fifteen feet from the goal, the student's perceived probability of success was at zero percent. At seven feet, the perceived probability was rated at a 52 percent chance of throwing a ring onto a stake, even though the observed probability in the study ended up at 23 percent. Therefore, Atkinson and Feather (1966) concluded that the students in the ring-toss experiment were overly optimistic in their expectation of success. In the classroom setting, a student who is overly optimistic as to his expectation of success on an upcoming examination may not devote the same quality or amount of time to studying as the students with a smaller perceived probability of success. This over-optimism could lead to lower exam scores overall.

The third component of Atkinson's achievement motivation framework is the incentive value of success. Incentive value is seen as the pride a person has in the accomplishment of a task, and it shares an inverse relationship with the probability of 
success (Atkinson, 1958). For example, tasks that are easily accomplished do not seem to generate as much pride in the achievement of the goal. However, tasks which are perceived to be more difficult, once they are achieved, generate an increased sense of pride and satisfaction (Atkinson, 1964). This pride and satisfaction can be an incentive to increase the likelihood that the achiever will pursue other such goals. For example, in the classroom setting, the time and effort that a student puts into successfully working through a complex, multi-step problem increases his or her value for the learning. This value would not be as high if the instructor simply handed out the same information on a flier and the student did not work for it.

The three factors, motive to achieve, expectancy of success, and incentive value share a joint function with the tendency to achieve success. This tendency is strongest when the perceived difficulty of a task is moderate and when the motive to achieve is high (Atkinson \& Raynor, 1974). In this case, a student would prefer a task that they perceive to be intermediate in difficulty. The preferred task falls between something that is so easy, success is guaranteed, to a task that is so difficult, success is impossible.

The expectancy-value theory may be particularly helpful to educational institutions in explaining the causes behind student behavior. The theory allows educators to account for multiple different needs that each student brings to school. These needs have been identified as the level of student aspiration (Lewin, 1935), student expectancies and values (Atkinson, 1958), and a student's ability perception (Wigfield \& Eccles, 1992). Achievement motivation theory in particular has been used to describe the motivational processes that can affect the success of students on cognitive tasks (Wolters, 2004). More specifically, achievement motivation theory accounts for types of behavior 
that occur when a student is aware that his or her performance is under evaluation. Inherent in the evaluation is a judgment of failure or success, which may affect the future motivational choices of the student (Atkinson, 1964).

Atkinson's definition of achievement motivation includes three components: motives, probability for success, and incentive value. These three components relate to the likelihood that a person may choose to engage in achievement tasks or become another 'failure to retain' statistic. This theory has helped researchers outline specific goal orientations that increasingly predict the reasons, as well as the causes, of goal oriented activity (Dweck, 1986).

\subsection{Achievement goal orientation}

There have been at least two main differences presented in the literature about how students come to develop different achievement goal orientations. Theorists have attempted to describe how students developed a preferred goal orientation in learning situations (Duda \& Nicholls, 1992). These researchers theorized that the type of goal orientation a student develops was a result of how each student perceived his or her academic ability. As has been previously referred to in this manuscript, if the student's perception is that his or her ability is fixed, the chance is greater that he or she will not succeed in the program. While at the same time, increased effort and task persistence ultimately lead to improved outcomes. Earlier, Nicholls (1975) had defined two categories of goals for students in an achievement setting, which were task involvement and ego involvement. Task involvement refers to the situation where students seek to develop competence relative to their own abilities, and ego involvement identifies students who seek to develop their competence relative to the abilities of others. Nicholls 
also believed that the goal orientation held by a student was the result of the possession of either an internal or external locus of control (Nicholls, 1975). Nicholls's theory builds on Rotter's continuum of motivation that focuses on the perception of control. On the other hand, at about the same time, Dweck and Repucci (1973) postulated a different set of reasons why students acted the way they did in learning situations.

In an attempt to find out how students perceived the relationship between his or her behavior and outcomes in an achievement setting, Dweck \& Reppucci (1973) found that some children facing repeated failure experienced a decline in performance while others in the same situation did not. The students whose performance declined with repeated failure displayed a 'helpless' response to the failure. The students whose performance did not decline when faced with failure were deemed to be using a mastery response pattern (Diener \& Dweck, 1980; Dweck \& Reppucci, 1973). From this research, theorists were able to group the patterns of responses from students and hypothesize specific goal orientations to help classify student goals for learning.

Dweck (1986) described how the development of an achievement goal orientation by students could stem from their personal beliefs about their intelligence, as previously alluded to in this manuscript. This came to be known as the personal theory of intelligence, which is the belief held by an individual about whether he or she is able to increase his or her intelligence. If a student believes that his or her intelligence is fixed, he or she will typically adopt what is known as a performance goal orientation. A student, who believes that his or her intelligence is dynamic, or malleable, is more likely to develop what is known as a mastery goal orientation (Dweck, 1986). These two classes of goals, performance and mastery, which were derived from achievement motivation 
theory, have been useful for identifying the motivational needs as well as causes of goaloriented behavior of students in the classroom (Pintrich, 2000). Students have reasons, or purposes, for achievement in academic settings. These reasons, combined with a type of self assessment, are hypothesized to form a goal orientation (Ames \& Archer, 1988; Grant \& Dweck, 2003). Understanding a student's goal orientation, or where he or she falls on the continuum from performance to mastery, can help explain his or her underlying need for achievement in learning along with how he or she would approach that objective.

A mastery goal orientation is typically represented by students who seek to acquire and develop increased competence and who set challenging learning goals for themselves (Zweig \& Webster, 2004). They also predict student persistence over time (Harackiewicz, Barron, Tauer, Carter, \& Elliot, 2000; Mattern, 2005) and lead students to increase their ability over time (Elliott \& Dweck, 1988). Students who adopt a mastery goal orientation in a learning context appear to attribute successes or failures to the amount of effort they put into the task (Ames \& Archer, 1988). In a study including one hundred and seventy-six randomly selected junior and high school students, Ames and Archer (1988) reported that the students who perceived the use of a mastery goal orientation for learning also reported using more effective study strategies, preferred more difficult tasks, and maintained a more positive attitude in the class.

Performance goal orientations are typically represented by students seeking to appear talented, or at least, to perform better in relation to other students (Senko, Hulleman, \& Harackiewicz, 2011). In their study with one hundred seventy six junior and high school students, Ames and Archer (1988) gathered information about the students' 
achievement goals and how the use of those goals were specific to certain motivational processes. The researchers used self-report, survey type instruments with the students involved in the study. One sequence of findings that Ames and Archer (1988) report is that students using a performance goal orientation are the students in class who are primarily concerned about their grade. These same students will also typically attribute success or failure in the class to their ability (Ames \& Archer, 1988). In a separate, but parallel line of study, Elliott and Dweck (1988) were publishing some research they had completed with one hundred and one fifth grade students. In this study, each student encountered an experimenter who gave instructions, presented learning tasks, and recorded results (see following paragraph). These researchers found that the students who used a performance orientation focused on the "adequacy of their ability" (Elliott \& Dweck, 1988, pg 5). These students normally declare the reason they did well on a test is because they are smart, which is a fixed ability view, and they use their grade on a test to let others know that they are intelligent, which is evidence of a performance orientation. Conversely, in the face of failure, these students attribute poor performance to their lack of ability, which is a fixed ability view.

\subsection{Factor analysis}

It may be useful to review briefly the methodology behind factor analytic solutions that are mentioned so often in this literature review. With factor analysis, a large number of test items are correlated with each other. The job of the researcher, and the statistical software doing the analysis, is to find the latent, or unseen, structure behind the correlated data. The question asked in factor analytic work is if there exists a small number of common factors behind the numerous data points that explain a large amount 
of the variance. It is the researcher themselves, such as Elliot and Dweck, who look at the collection of raw test items that load, or correlate, on a particular factor and call what they are seeing a mastery or performance orientation. As can be seen, construct validity for these invented factors builds up over time with other studies that confirm or refute these factor structures.

The mastery and performance orientations outlined above are two approaches to learning used by students in achievement settings, such as school. In achievement motivation research (Elliot, McGregor, \& Gable, 1999), these orientations are factors that may account for certain types of study strategy use and grade achievement by individual students. Therefore, mastery and performance orientations formed a two-factor model used to describe achievement motivation (Dweck \& Reppucci, 1973; Diener \& Dweck, 1980). Methods associated with factor analytic work will be explained later in this manuscript.

The way in which theorists have understood achievement goal orientation has evolved since the mastery and performance goal constructs, or the two factor model, were first introduced. In general, there was a mixed pattern of results observed in the data coming from the performance goal factor (Elliot, 2005). Researchers visualized some students as being more successful in achievement settings while others who also used performance goals were not. Elliot and Harackiewicz (1996) asked eighty-four university undergraduate students to solve puzzles in four distinct and controlled achievement contexts. Three contexts were set up to bias the students towards using either a performance-approach, performance-avoidance, or a mastery goal orientation. The fourth context served as the control in which no specific goal orientation was introduced. 
Afterward, the students responded to two questionnaires that helped researchers identify involvement, effort, and perceived competence. The researchers found that the performance goal orientation construct included students who used two separate types of goals, some students using approach goals and others using avoidance goals for learning. As the difficulty of a task increases, students resort to a performance-avoidance disposition due to increased fear of failure (Elliot \& Church, 1997). The 'noise' from this and other research led to the increased use of an approach and avoidance distinction for the performance construct.

A student using a performance-approach goal orientation would focus on outperforming others, appearing talented (Senko, Hulleman, \& Harackiewicz, 2011), or attempting to demonstrate his or her high ability (Elliot \& Church, 1997). A student demonstrating a performance-avoidance goal would focus on not appearing incompetent or less talented in relation to classmates (Elliot \& Harackiewicz, 1996), and avoiding a worse performance than others (Elliot \& Church, 1997; VandeWalle, 1997). This division of the performance goal construct created the trichotomous goal framework, which includes mastery, performance-approach, and performance-avoidance goals. Continued research validated the superiority of the trichotomous goal framework over the original two factor model (Elliot, McGregor, \& Gable, 1999; Zweig \& Webster 2004).

Zweig \& Webster (2004) created the Goal Orientation Measure by using twenty items from Button, Mathieu, \& Zajac's (1996) goal orientation scale, as well as two items from Elliot \& Church's (1997) achievement goal scale. Zweig \& Webster (2004) added ten items of their own to the instrument. This new thirty-two item instrument comprised their initial measure of goal orientation. The new Goal Orientation Measure was tested 
with undergraduate students enrolled in a Management Sciences course and an Introductory Psychology course. Specifically, Zweig \& Webster found that their threefactor solution provided for the highest value of total R-squared between the predictor and criterion while still satisfying statistical goodness of fit models.

\section{$2.122 \times 2$ Goal orientation framework}

Once the performance goal orientation was split into performance-approach and performance-avoidance goal constructs, and was more successful at predicting student outcomes, Elliot and McGregor (2001) split the mastery goal orientation approach into a mastery-approach and mastery-avoidance goal construct (See Figure 2-2). They posited that achievement theorists had previously overlooked the mastery-avoidance goal factor. Up to that point, most theorists had presumed that mastery goals represented only an approach form of regulation. To confirm their suspicion, Elliot and McGregor (2001) surveyed a total of 180 undergraduate students with an expanded version of the achievement goal questionnaire that included the mastery-avoidance factor. They found that mastery-avoidance was indeed empirically separate from the mastery-approach factor. An example of a student representing a mastery-approach goal would include learning the material and applying it to information already learned for use in the real world. A mastery-avoidance example would appear as a student trying to avoid making any mistakes, avoid doing worse than before, or avoiding losing his or her skills. After performing a factor analysis, which is used to identify underlying relationships between each construct, the researchers found the goal constructs to be empirically distinct from each other. For the purposes of this study, the researcher used the trichotomous goal 
framework instead of the $2 \times 2$ model in order to obtain the most parsimonious explanation of the variance.

Figure 2-2

$2 \times 2$ Framentork

\begin{tabular}{|c|c|c|c|}
\hline & \multicolumn{3}{|c|}{ Definition } \\
\hline & \multirow{3}{*}{$\begin{array}{l}\text { Approaching } \\
\text { success } \\
\text { Avoiding } \\
\text { failure }\end{array}$} & Mastery & Performance \\
\hline \multirow{2}{*}{ Valence } & & $\begin{array}{l}\text { Mastery- } \\
\text { approach goal }\end{array}$ & $\begin{array}{l}\text { Performance- } \\
\text { approach goal }\end{array}$ \\
\hline & & $\begin{array}{l}\text { Mastery- } \\
\text { awoidance } \\
\text { goal }\end{array}$ & $\begin{array}{l}\text { Performance- } \\
\text { avoidance goal }\end{array}$ \\
\hline
\end{tabular}

While common sense may indicate that students who adopt a mastery goal orientation for learning would typically outperform other students, this is not always the case. Students who use mastery goal orientations for learning may not always achieve as high a grade as students who adopt a performance goal orientation. Researchers looking into this apparent discrepancy report that mastery-oriented students may become sidetracked into areas that interest them, and may not concentrate on the material that will eventually be tested (Senko \& Miles, 2008). This could potentially lead to lower examination scores for these students than might be otherwise expected. However, the body of research pertaining to achievement goals is replete with statistically significant findings between mastery goal orientations and examination score (Luo, Paris, Hogan, \& Luo, 2011; Wolters, 2004; Dupeyrat \& Mariné, 2005; Grant \& Dweck, 2003). To be entirely clear, the purpose of this project is not to suggest that pining after grades is something that is universally desirable. Rather, the purpose is to investigate the 
relationships between achievement goal motivation, student study strategy factors and actuai outcomes on a high-stakes graduate student anatomy examination. While grades may not be the best assessment to demonstrate academic learning, they have been " $a$ commonly accepted proxy measure" (Handelsman, Briggs, Sullivan, \& Towler, 2005, pg 188).

There have been many studies that have established a correlation between mastery goal use and improved grades (Dupeyrat \& Mariné, 2005; Grant \& Dweck, 2003; Luo, Paris, Hogan, \& Luo, 2011; Woiters, 2004). In one of the most recent reports, Jones, Wilkins, Long, \& Wang (2012) reported that mastery goals predicted positive study strategies $(r=.57, p<.001)$, and positive strategies predicted students' current math grade $(r=0.21, p<.01)$. They included 163 ninth-grade algebra students in their study. The students completed a survey that assessed items such as intelligence and effort beliefs, mastery and helpless responses to failure, interest value in the subject for the class, the student grade in the course, and demographic information.

There has been some opposition to the use of achievement goals to explain achievement behavior in school (Huang, 2012). One reason for the resistance to use achievement goals is due to inconsistent results in the correlation between academic achievement and achievement goals. However, the studies from which these results come vary in the age and other demographics of the studied student population. In Huang's 2012 meta-analysis, he reports that "when mastery, performance-approach, and performance-avoidance goals were regressed on academic achievement, all regression coefficients ... yielded $\mathrm{R}^{2}=.04$ " $\mathrm{p}<.05$ (pg 63). However, the working premise of this 
project is that this theoretical construct has not yet been sufficiently explored. In other words, it may be too early to entirely dismiss the achievement goal construct.

In an effort to explain more of the significance of achievement goals, Elliot, McGregor, \& Gable (1999), Fenollar, Román, \& Cuestas (2007), and Simons, Dewitte, \& Lens (2004) looked at undergraduate students' study strategies and how they affected the relationship between achievement goal orientation and examination performance. As will be shown in the next section, this research revealed statistically significant correlations between achievement goal and study strategy factors. There were also statistically significant correlations between study strategy factors and grades on an examination for undergraduate students.

\subsection{Study strategies}

Students typically use different techniques for studying while in school. If a student learns best while discussing the course material with someone else, that student may use a strategy for learning that includes study group sessions. Another student may do well with learning by reading the textbook and making detailed notes. Even still, a different student may find that he or she learns best by diagramming the course information on a dry-erase board. A student may also study by reading and re-reading the same passages of required text. Each of these previously mentioned students is using a study strategy to aid in learning the course information.

Researchers have grouped study strategies that students use into two main approaches, deep-processing and surface-level processing (Nolen, 1987). Nolen (1987) performed a correlational study between learning goals and study strategies with collegeage students and students in the eighth and eleventh grades. Of the groups of students, the 
college-age group was more inclined to use surface-level and deep-processing strategies more than the younger students did in their study habits (Nolen, 1987). Students using deep-processing study strategies are those who generally apply the new information to what they already know. These students also tend to maintain open communication with instructors, as well as monitor their own comprehension (Robbins et al., 2004). The level of processing usually indicates that there are degrees of mental analysis behind the learning process (Craik \& Lockhart, 1972). For students who exhibit deep-level processes, once a word or scenario has been recognized, they generally associate it with images, stories, or their experiences. The more the information is processed, the deeper the strategy is said to be (Craik \& Lockhart, 1972). Nolen (1987) and Robbins et al. (2004) have found evidence that deep-processing study strategies may be statistically related to improvement in examination grades and grade point averages in school. The other main study strategy approach, surface-level processing, appears to be a lesseffective strategy for studying. This strategy can be observed when students simply read and re-read passages, memorize new words, and repeat informational facts (Nolen, 1987). Students who use surface-level study strategies may memorize parts they do not understand, rehearse the material until it can be repeated word-for-word, skip over parts they think the teacher will not ask questions about, or parts they do not find important (Simmons, Dewitte, \& Lens, 2004). Nolen (1987) found that having a goal to outperform other students $(r=.39, p<.001)$ as well as trying to avoid the work of studying $(r=.26$, $p<.05)$ are both correlated with high utility ratings of surface level strategies.

In their research, Elliot, McGregor, \& Gable (1999) performed two separate studies that addressed college undergraduate achievement goals as predictors of study 
strategies. They assembled a study strategy questionnaire partially from existing measures as well as creating new, more applicable items to the student population. Pilot studies helped derive the final measures of study strategies, which ended up being deepprocessing, surface-processing, and disorganization. Each of these measures included five items that the participants would respond to on a one (not at all true of me) to seven (very true of me) scale. Once again, the methodological tool used for these measures was factor analysis. In the Elliot, McGregor, and Gable study (1999), each statement from the questionnaire loaded onto the study strategy factor of deep-processing, surfaceprocessing, or disorganization, and accounted for $59 \%$ of the total variance.

\subsection{Achievement goals and study strategies}

Deep-processing study strategies may be predicted by the type of achievement goal orientation a student uses (Elliot, McGregor, \& Gable, 1999). For example, a student who uses a mastery goal orientation typically uses deep-processing study strategies when studying for an examination $(r=.38, p<.01)$ (Elliot, McGregor, \& Gable, 1999). More specifically, a mastery goai oriented student challenges him or herseif to learn new concepts and then, while studying, finds ways to apply the new information to situations he or she has experienced. In comparison to using a mastery goal orientation, using a performance-approach goal orientation is not correlated with deep-processing study strategies and using a performance-avoidance goal orientation is negatively correlated to deep-processing $(r=-.28, p<.01)$ and examination performance $(r=-.30, p<.01)$ (Elliot, McGregor, \& Gable, 1999).

In a meta-analytic work, Robbins et al. (2004) listed achievement motivation ( $\mathrm{r}=$ $.303, p<.05)$ and academic self-efficacy $(\mathrm{r}=.496, p<.05)$ as two of the strongest 
predictors of grade point average for students in college. These predictors were compared with other commoniy accepted predictors such as socioeconomic status, high school grade point average, standardized test scores, and financial support (Robbins et al., 2004). In another meta-analytic study that included 344 independent samples and represented 72,431 individual students, Crede and Kuncel (2008) assessed the construct and predictive validity of study skill strategies versus other variables to determine undergraduate students' grades. They identified that a student's study strategy was a more effective predictor of academic success in college than previous grade point average and standardized tests (Crede \& Kuncel, 2008). These two predictive factors, namely achievement motivation and study strategies, along with their management in the classroom, may make it possible to significantly affect the academic performance of a student.

In some instances, there may be educational phenomena that do not translate readily into educational interventions. For example, dispositions such as locus of control (Rotter, 1966) appear to be relatively stable and somewhat un-malleable by outside agents. However, Ames (1992) makes the argument that instructors can incorporate classroom tasks with features that encourage students to adopt a mastery goal orientation. The focus in the classroom is on effort-based strategies to help the students focus on their personal effort rather than on ability (Ames, 1992). Also, the type of incentive structure built into a course may affect the achievement goal orientation that students will adopt (Covington, 2000). In a review of the motivational dynamics of school achievement, Covington (2000) reports that the quality of learning and the amount of persistence displayed by students in learning is a mixture of three things: the student's goals for 
learning, the motivational value of those goals, and the classroom reward structure.

Finally, Brophy (1999) speaks to the idea that if teachers were able to assist students to apply what they were learning to their personal lives, they could facilitate the adoption of a mastery goal orientation by those students.

Similarly, the study strategies of students have also been shown to be malleable in the classroom. Broekkamp and Van Hout-Wolters (2007) identify a number of techniques that a classroom instructor might use to help students in general apply more effective study strategies. The techniques are simple and do require that the instructor communicate the expectations well to the students. For example, some techniques include helping the students change their routine for studying or reading a text from an alternate perspective.

It has been shown that undergraduate students using a mastery goal orientation in conjunction with a deep-processing study strategy have achieved higher grade levels in college (Elliot, McGregor, \& Gable, 1999). Ames and Archer (1988) have written about the potential differences between performance and mastery goals that students held for learning and what effect those differences might have on the student's use of effective study strategies. They report that students who employed a performance goal orientation would typically attribute success or failure on a task to their ability. Consider this example: Mary scores well on a math test overall but she incorrectly answers the only two story problems on the test. She states, 'I did well on the test because I am smart, but I just cannot do story problems', In this statement, she attributed outcomes to her ability as well as demonstrated the use of a performance achievement goal. 
Students who adopt mastery goal orientations use more effective study strategies, and regardless of success or failure, they attribute the outcome to the amount of effort they put into the task. Here is the same scenario with Mary now attributing the outcomes to her effort: 'I did well on the test because I studied hard, but I did not put much time into story problems'. Students who use a mastery goal orientation in school have shown consistent results suggesting that the use of mastery goals "may foster a way of thinking that is necessary to sustain student involvement in learning as well as increase the likelihood that students will pursue tasks that foster increments in learning" (Ames \& Archer, 1988, p. 264). The results in this line of research have helped theorists understand that students who use a mastery goal orientation typically demonstrate increased motivation and improved achievement outcomes compared to students working with a performance goal orientation (Schunk, 1996). The difference in motivational levels and achievement outcomes with fourth-grade students became clear in a two-part study conducted by Schunk (1996). Schunk (1996) discovered that students learning under conditions consistent with a mastery goal orientation developed increased motivational levels and achievement outcomes than those learning under conditions consistent with a performance orientation.

There is research that indicates classroom instructors may affect the type of achievement goal strategy that a student will use (Ames, 1992; Roeser, Midgley, \& Urdan,1996; Svinicki, 1999). Roeser, Midgely, \& Urdan (1996) used a sample of 296 eighth-grade students for their research involving achievement goals and feelings of belonging and how these affect academic grades. They correlated a student's perception of classroom goal structure with the goal orientation that the student develops for use in 
the class ( $r=.40, p \leq .01)$. A general rule posited by Ames (1992) that may help students adopt a mastery achievement goal orientation is to focus on effort rather than ability in the classroom. Research has also shown that faculty can assist students to improve their academic performance by helping them realize what their learning weaknesses are and how to address those weaknesses (Sizoo, Agrusa, \& Iskat, 2005). As educators in the hospitality industry, Sizoo, Agrusa, and Iskat (2005) focused on how they could best help their adult students continue to learn by improving their study skills. Again, Crede and Kuncel (2008) report that students who improve their study strategies would expect that grades, or college performance, would improve as well. While grades may not be the best assessment to demonstrate academic learning, they have been a commonly accepted proxy measure (Handelsman, Briggs, Sullivan, \& Towler, 2005). Even though there were no specifics provided, Ramist (1981) reported for the College Entrance Examination Board that, while controlling for other variables, the relationship between study strategies and college performance (grades) appears to lead to an increase in graduate student retention. Solomon (2000) also indicated that an organized and effective faculty could help improve undergraduate student retention rates.

\subsection{Achievement motivation theory may help explain success in school}

Researchers have a long history of appealing to motivation constructs to help them understand what measures of cognition have not completely explained. Achievement goal orientation has been recognized as a useful tool for understanding how students develop, attain, or demonstrate competence in learning and performance. In an academic achievement setting, students gravitate towards using either a mastery or performance goal orientation. Using examination performance as a variable, Grant and 
Dweck (2003) performed a total of four studies along with a longitudinal study in a challenging undergraduate premed course. The impact of each of the goal types used by the students depended on how they operationalized the goals on an individual basis. Grant and Dweck (2003) reported that undergraduate students who used mastery goals appeared to be more successful in school. Additional research using undergraduate students has shown that those who use mastery goals may develop an increased understanding and interest in the material, as well as using more effective study strategies (Mattern, 2005). The analysis of achievement goal dispositions, coupled with an analysis of study strategies, may help account for additional student academic achievement above and beyond what achievement motivation measures alone might teach us.

Deep-processing of information by students may produce increased understanding and retention of information over surface-processing strategies (Phan, 2009). In a study that proposed and tested a model of relationships between achievement goals, study strategies, and academic performance, Phan (2009) included 275 undergraduate students from an educational psychology course. Elliot, McGregor, and Gable (1999) reported that the correlation between using a mastery goal orientation and a deep-processing study strategy for undergraduate students is positive and statistically significant $(r=.45, p<$ $.0001)$. They also reported that there was no correlation found between a student's use of a mastery goal orientation and surface-processing study strategies. Deep-processing study strategies have shown "strong and robust relationships with academic performance in college" through the use of grades on examinations (Crede \& Kuncel, 2008, p. 439). Higher grades on examinations overall may lead to improved course grades that could help lower attrition levels for graduate students. 


\subsection{Summary}

This literature review focused on retention and attrition of graduate students, achievement motivation theory, goal orientation, study strategies, and success of graduate students on an examination. Achievement motivation theory has helped us determine the reasons behind student motivation (Senko, Hulleman, \& Harackiewicz, 2011). The constructs of achievement goal orientation are mastery and performance goals (Dweck, 1986; Elliot \& Church, 1997). These goals describe the achievement motivation of students and can be predictive of academic performance (Harackiewicz et al, 2000; Robbins et a1., 2004). The first purpose of this project was to identify the correlation between achievement goal use and examination performance for first-term graduate students at the University of St. Augustine. Achievement goal orientation may predict a certain type of study strategy used by students, while poor study strategies along with maladaptive achievement goal orientations have led to poor academic performance (Elliot, McGregor, \& Gable, 1999; Nolen, 1987; Robbins et al., 2004). Poor graduate student academic performance in professional doctorate programs has been associated with attrition from the program (Andrews, Johansson, Chinworth, \& Akroyd, 2006). The second purpose of this project was to identify the relationship between achievement goal use and the type of study strategies used by first-term graduate students at the University of St. Augustine to prepare for an examination. 


\section{Chapter Three}

\section{Research Design and Methodology}

\subsection{Introduction}

The problem, as identified in chapter one, is that professional graduate student programs have relatively low completion rates. Poor completion rates come at a significant cost to the university and student alike. University admission officers have established criteria to aid in selecting the students who are most likely to succeed in the program. Admission criteria such as previous grades, standardized test scores, and interview performance that are typically used in prospective student selection may not be the best criteria on which to base the decision of acceptance to the program.

As a theoretical framework for looking at student retention, achievement goal orientation may account for success or failure with undergraduate students, but has not been fully tested with graduate students. The purpose of this study is to collect data to investigate the relationships between achievement goal motivation, study strategy factors, and actual outcomes on a high-stakes graduate student anatomy examination. It is hypothesized that both achievement goal orientations and study strategies may add additional explanation power to questions of student retention. Achievement goal orientations, along with study strategies may be additionally helpful criteria to identify students most likely to succeed in graduate programs.

Achievement goal orientation has been useful for researchers to explain the purposes of students in learning situations. Researchers have correlated different types of achievement goal use with certain types of study strategy use by students. The 
combination of achievement goal orientation along with the type of study strategy use may help to explain more of the causes behind graduate student attrition.

\subsection{Questions}

There were two main questions included in this study. First, the researcher wanted to identify the correlation, if any, between achievement goal use and the resultant grade on an examination for first-term physical and occupational therapy students. Secondly, the researcher wanted to explain the correlation between achievement goal and study strategy use in preparation for an examination.

The two questions for this study were:

1. Does performance on the Goal Orientation Measure instrument of achievement motivation explain variance in examination performance for first-term graduate students at the University of St. Augustine?

2. Does performance on the Goal Orientation Measure instrument of achievement motivation explain variance in the type of study strategies used by first-term graduate students at the University of St. Augustine to prepare for an examination?

\subsection{Hypotheses}

There were nine hypotheses for this study as well as three secondary hypotheses:

1. There is a statistically significant and positive correlation between measures on the mastery goal factor and the performance-approach goal factor.

2. There is a statistically significant and negative correlation between measures on the mastery goal factor and the performance-avoidance goal factor. 
3. There is a statistically significant and positive correlation between student reports of a mastery goal factor and a deep-processing study strategy factor.

4. There is a statistically significant and positive correlation between student reports of a performance-approach goal factor and a deep-processing study strategy factor.

5. There is a statistically significant and positive correlation between student reports of a performance-avoidance goal factor and a surface-processing study strategy factor.

6. There is a statistically significant and positive correlation between student reports of a performance-avoidance goal factor and a disorganized studying strategy factor.

7. There is a statistically significant and positive correlation between student reports of persistence in studying and a mastery goal factor.

8. There is a statistically significant and positive correlation between student reports of persistence in studying and a deep-processing study strategy factor.

9. There is a negative and statistically significant correlation between examination scores and measures on the performance-avoidance goal factor.

10. There is a negative and statistically significant correlation between examination scores and student reports of a disorganized studying strategy factor.

\subsection{Secondary hypotheses}

1. There is not a statistically significant comparison between the means of gender and examination score. 
2. There is not a statistically significant comparison between the means of gender and discipline.

3. There is not a statistically significant comparison between the means of discipline and examination score.

\subsection{Population and sample}

The student population used in this study came from the University of St. Augustine for Health Sciences enrolled in a face-to-face traditional classroom course. The University offers a physical and occupational therapy professional graduate degree, as well as a dual degree that includes both physical and occupational therapy degrees. The University is located in St. Augustine, Florida, along the eastern coast of the United States. Every graduate student in his or her first term is required to take the Applied Human Anatomy course, and each of these students had the opportunity to participate in the study. Thirty-nine first-term graduate students participated in the study, which was the total population as the sample. The University of St. Augustine has reported an 80.4 percent graduation rate for their physical therapy students, and a 77.3 percent graduation rate for their occupational therapy students for the years 2009 through 2011 (University of St. Augustine, 2012).

\subsection{Ethical considerations}

The University of St. Augustine for Health Sciences has a well-outlined institutional review board process. For this project to be approved, it needed to be explained in written form including the significance and specific aims, funding source, research plan, potential benefits and risks to the participants. The institutional review board approved the project on $6 / 7 / 2012$. The students were informed that they were free 
to not participate and were under no threat that the decision to not participate would influence their grade or status in the class or harm them in any way. Confidentiality of the student participants was maintained at all times. All information obtained in this study was strictly confidential unless disclosure was required by law. Students did not include their names on the questionnaire forms. Only members of the immediate project staff had direct access to the information. When not in use, the paper information was locked in a safe and the electronic data was password protected.

\subsection{Generalizability}

The theoretical population for this study consists of graduate students seeking a physical or occupational therapy degree. The sample in this study might be generalized to other cohorts of graduate students at the University of St. Augustine; however, issues of generalization were not a major goal of this project. The researcher chose the Human Anatomy course for analysis in the study due to three reasons: first, the requirement that every student take the class; second; that the course is offered during the students' first term; and third, due to its level of difficulty. The second anatomy test of the course was recommended by the course instructor for use in this study because it has traditionally been one of the leading indicators for students who tend to continue successfully in the program and may identify those who may need to go to part-time status or otherwise may have difficulty moving forward. Using the second examination also allowed the students a previous experience with the instructor's testing methods and gave the students a chance to review their study strategy use for the first examination. As mentioned previously, student retention rates at the University of St. Augustine for Health Sciences range between 80 to 90 percent, and as such, the actual sample in this study is obviously 
not representative of the types of students and graduate programs that are reporting poor retention values in general. However, the intent in this study was to test the boundary conditions of the theoretical constructs under investigation while questions of generalizability were of secondary consideration.

\subsection{Data collection and instrumentation}

Each student that participated in the study was asked to fill out a total of three questionnaires. Two days prior to the examination, every student filled out the first two questionnaires, which assessed their achievement goal orientation, study strategy, and persistence in preparation. The final questionnaire, which assessed student effort in studying, was filled out three days after the examination. The researcher was able to connect the questionnaires and the examination results to the correct student using the test number, age, gender, and birth month provided by each participant.

As previously stated in chapter two, the Goal Orientation Measure underwent various revisions that took it from thirty-two items to twenty-one items that remained the most valid. The questionnaire contained seven items for each of the three achievement goal factors: performance-approach, performance-avoidance, and mastery. The internal consistency reliabilities, or Cohen's Alpha, for the three factors were determined to be as follows: performance-approach orientation $(\alpha=.82)$, performance-avoidance orientation $(\alpha=.69)$, and mastery orientation $(\alpha=.85)$ (Zweig \& Webster, 2004). This same twentyone item questionnaire was used for the purposes of this study and can be found in Appendix A.

On the Goal Orientation Measure, found in Appendix A, the first seven statements allowed the researcher to quantify the amount that students used a performance-approach 
orientation to learning while preparing for the examination. An example of a performance-approach orientation statement from the questionnaire was, 'I value what others think of my performance.' Statements eight through fourteen identified the amount that students used a performance-avoidance orientation to learning while studying for the examination. An example of a performance-avoidance statement from the questionnaire was, 'I avoid tasks that I may not be able to complete.' The last statements on the first survey numbered fifteen through twenty-one, which helped the researcher identify the amount that students used a mastery goal orientation in preparation for the examination. An example statement that indicated a mastery goal orientation was "The opportunity to do challenging work is important to me.' Scores for each factor were added together to form a composite factor variable. This composite score was used in the testing of the hypotheses listed above.

On the second questionnaire, found in Appendix B, statements numbered one through five allowed the researcher to identify the amount that students used deepprocessing study strategies in preparation for the examination. An example of a deepprocessing statement was, 'I try to think through topics and decide what I am supposed to learn from them, rather than studying topics just by reading them over.' Statements numbered six through ten allowed the researcher to identify the amount that students used a surface-processing study strategy in preparation for the examination. An example of a surface-processing statement was, 'I study for this course by memorizing the definition at the end of each chapter of the text.' The statements numbered eleven through fifteen allowed the researcher to identify students who primarily used a disorganized study strategy in preparation for the examination. An example of a disorganized study strategy 
from the questionnaire was, 'I often find that I don't know what to study or where to start.'

The final section of statements on the second survey included numbers sixteen through nineteen. These statements measured the amount of persistence a student reported using while preparing for the examination. An example of a persistence statement was 'When something that I am studying gets difficult, I spend extra time and effort trying to understand it.' This second questionnaire is located in Appendix B.

The effort questionnaire consisted of two statements. The statements were answered on a scale from 1 (not at all true of me) to 5 (very true of me) scale. The two items were 'I put a lot of time into preparing for the exam' and 'I worked very hard to prepare for the exam.' For this study there was no meaningful variance discovered in the data from the final questionnaire. Due to the non-significance of effort in these results, there will be no further mention made of the third questionnaire or the variable of effort through the remainder of this report. The effort questionnaire can be found in Appendix C.

\subsection{Research design and data analysis}

All hypotheses in this study were investigated using version eighteen of the Predictive Analytics Software (SPSS, Inc., 2009). For all dependent measures and the categorical variables such as gender and degree sought, were analyzed as analysis of variance (ANOVA). The co-relationship between the various predictive variables and the dependent measure were analyzed as correlations as well as its more robust expression, regression. 
In statistical analysis, correlation and regression provide an estimate for the degree of association between two or more variables (Read, 2000). For the purposes of this study, correlation and regression methods were used to establish the amount of association between the variables. The investigators chose this particular statistical method to help identify the association between achievement goal and study strategy constructs, persistence, and examination scores of professional first-term graduate students. Specifically, the goal was to find out how much variance in the examination score could be accounted for by the various predictor variables in this study

Correlational analyses were performed to examine the relationships between the predictor variables in the study. The performance-approach, performance-avoidance, and mastery achievement goal factors were tested to determine the degree that they were inter-correlated. These achievement goal factors were also correlated with individual examination scores as well as study strategy factors. Study strategy factors were correlated with examination scores. Persistence and effort were correlated to each other as well as to examination score, achievement goal and study strategy factors.

Analysis of variance, more commonly referred to as ANOVA, is useful in comparing the means of two or more samples (Read, 2000). For the purposes of this study, ANOVA was used three times. First, the means of the differences between the three disciplines and examination score were compared. Second, the means between gender and discipline were compared with ANOVA. Third, the means were compared between gender and examination score. 


\subsection{Summary}

First-term graduate students enrolled at the University of St. Augustine for Health Sciences were questioned about the second Human Anatomy course examination to examine the correlation between achievement goal factors, study strategies, persistence, effort, and examination performance. Each first-term physical, occupational, and dual therapy student who was invited to participate in the study ultimately participated. Three questionnaires were used to gather the information about each student's use of goal orientation, study strategies, and persistence.

\subsection{Limitations and delimitations}

There are some potential limitations to this study, mostly found in methodological and sample-related factors. First, the data gathered was strictly quantitative, and was reported as numbers to represent the achievement goal, study strategy, persistence, and effort categories. These were measured with pre-established, close-ended questionnaires. Therefore, there was no opportunity for the students to explain or qualify their responses. Second, the questionnaires were initially developed for use with undergraduate rather than graduate students. It is the stated goal of this research to determine if established theoretical and empirical associations hold true in a post-graduate professional setting with a highly demanding examination. It is possible that the sample used in this study was so homogeneous relative to the variables under investigation that meaningful effects were not found. It is also possible that the constructs were not sensitive enough to find effects with this particular population. In addition, the small sample size utilized for the study may have led to the lack of some expected findings between some relationships. Using a larger sample size may have helped demonstrate significance with the small to 
medium effect sizes as compared to the large effect sizes. Therefore, while small and medium effect sizes may have been present, the small sample size might have precluded their significance. The last methodological concern relates to assumptions underlying the study. Intrinsic to the study is the assumption that achievement goal orientation, study strategies, persistence, and effort exert a causal influence on examination scores.

It is important to note that the statistical analyses used in this study were primarily correlational. Therefore, no definitive causal inference can be drawn from these results. Experimental analysis was not used in this study due to the inherent difficulties and ethical issues of manipulating a student's achievement goal orientation, study strategies, and amount of persistence to produce improved or inadequate results on an examination.

With regard to sample-related factors, the study included only first-term. professional graduate students in Florida. When issues of generalizability are discussed, these results were not meant to be generalized to other student populations. The specific intent was again to test the boundary conditions of the theoretical constructs of the achievement motivation theory to see if they would hold true with a population at the extremes of student life. 


\section{Chapter Four}

\section{Analysis of Data}

\section{4.i Analysis of data}

The main intent of this study is to test the boundary conditions of the achievement motivation theory while describing the correlations between graduate students' achievement goal factors, study strategy factors, and examination performance at the University of St. Augustine for Health Sciences. The combination of achievement goal orientation along with the type of study strategy use may help to explain more of the causes behind the relatively high rates of graduate student attrition. As mentioned elsewhere, attrition rates for the current subject population are exceedingly low. However, for the purpose of testing the boundary conditions of the theories under investigation, the current study population is suitable. Sections within this chapter include: Respondent Demographics, Discipline Comparison, Achievement Goal Factor Intercorrelations, Goal Orientation and Study Strategy Factors, Persistence, Examination Scores, and Summary.

The reader will be able to view the entire survey instrument in Appendix A, B, and C. However, the questionnaire information will be presented here in the interest of clarification, to provide the context in which the students responded to the surveys. The following is a direct quote from instructions to the student on each of the three questionnaires. 'Fill in the bubble on the scan-tron card that most appropriately reflects yourself along the continuum from $\mathrm{A}=$ Not at all true of me, to $\mathrm{E}=$ Very true of me. Thank you for your time.' 
Questions on the first survey identified the student's goal orientation factor, which were grouped into three variables: mastery, performance-approach, and performanceavoidance factors. Questions on the second survey identified the student's report of study strategy use and were grouped into three variable factors: deep-processing, surfaceprocessing, and disorganization. The student factor of persistence was also included on the second questionnaire. Questions on the third questionnaire identified the student's report of effort in preparing for the examination they had recently completed.

The data gathered from the questionnaires was reported as descriptive statistics, correlational analyses, and analysis of variance (ANOVA). All descriptive, correlational, and ANOVA statistics were analyzed with version 18 of the Predictive Analytics Software (SPSS, Inc., 2009). The individual statistics will be presented as an introductory sentence or paragraph and will include a correlating hypothesis, if applicable. Following each section of text, the corresponding data will be presented in table format. The hypotheses are listed below for ease of reference.

\subsection{Hypotheses}

1. There is a statistically significant and positive correlation between measures on the mastery goal factor and the performance-approach goal factor.

2. There is a statistically significant and negative correlation between measures on the mastery goal factor and the performance-avoidance goal factor.

3. There is a statistically significant and positive correlation between student reports of a mastery goal factor and a deep-processing study strategy factor. 
4. There is a statistically significant and positive correlation between student reports of a performance-approach goal factor and a deep-processing study strategy factor.

5. There is a statistically significant and positive correlation between student reports of a performance-avoidance goal factor and a surface-processing study strategy factor.

6. There is a statistically significant and positive correlation between student reports of a performance-avoidance goal factor and a disorganized studying strategy factor.

7. There is a statistically significant and positive correlation between student reports of persistence in studying and a mastery goal factor.

8. There is a statistically significant and positive correlation between student reports of persistence in studying and a deep-processing study strategy factor.

9. There is a negative and statistically significant correlation between examination scores and measures on the performance-avoidance goal factor.

10. There is a negative and statistically significant correlation between examination scores and student reports of a disorganized studying strategy factor.

\subsection{Secondary hypotheses}

1. There is not a statistically significant comparison between the means of gender and examination score.

2. There is not a statistically significant comparison between the means of gender and discipline. 
3. There is not a statistically significant comparison between the means of discipline and examination score.

\subsection{Respondent demographics}

On each questionnaire, the students were asked to record their gender. In Table 41 , it can be seen that there were more females in the study than males. There were a total of thirty-nine respondents in this study.

\section{Table 4-1}

Gender Distribution of Respondents

\begin{tabular}{ll}
\hline & $n$ \\
\hline Male & 17 \\
Female & 22 \\
\hline
\end{tabular}


Respondents were asked to report their age (See Table 4-2).

\begin{tabular}{ll}
$\begin{array}{l}\text { Table 4-2 } \\
\text { Ages of Respondents }\end{array}$ \\
\hline & $n$ \\
\hline 21 & 1 \\
22 & 3 \\
23 & 6 \\
24 & 7 \\
25 & 7 \\
26 & 3 \\
27 & 5 \\
28 & 4 \\
29 & 0 \\
30 & 0 \\
31 & 1 \\
32 & 0 \\
33 & 2 \\
\hline
\end{tabular}

Along with a physical therapy and occupational therapy program, the University of St. Augustine also offers a dual program. The dual program allows students to earn a degree in both physical therapy and occupational therapy. The students enrolled in the dual program are considered within the occupational therapy school during their first term; however, the researcher thought it might prove interesting to report them out individually. Respondents were asked to report the degree program they were currently seeking (See Table 4-3). 
Table 4-3

Degree Respondents Were Seeking

\begin{tabular}{ll}
\hline & $n$ \\
\hline Occupational Therapy & 8 \\
Physical Therapy & 29 \\
Dual Degree & 2 \\
\hline
\end{tabular}

\subsection{Discipline comparison}

A comparison of the three disciplines (physical therapy, occupational therapy, and dual degree) was performed. A one-way ANOVA was used to test for a difference between the means of the three disciplines that students were seeking and their subsequent examination score. There was no statistical significance found between the three disciplines and examination score, $F=1.639, p=.142, p<.05$ (See Table 4-4).

Table 4-4

Difference between discipline and examination score

\begin{tabular}{lccccc}
\hline \multicolumn{1}{c}{ Discipline } & $d f$ & $S S$ & MS & $F$ & $p$ \\
\hline Between groups & 18 & 5.410 & .301 & 1.639 & .142 \\
Withingroups & 20 & 3.667 & .183 & & \\
Total & 38 & 9.077 & & & \\
\hline
\end{tabular}

There was.no significant difference found between the means of discipline and gender in this study, $F=1.143, p=.292, p<.05$ (See Table 4.5). 
Table 4-5

Difference between discipline and gender

\begin{tabular}{lrrrrr}
\hline \multicolumn{1}{c}{ Discipline } & $d f$ & \multicolumn{1}{c}{ SS } & \multicolumn{1}{c}{ MS } & \multicolumn{1}{c}{$F$} & \multicolumn{1}{c}{$p$} \\
\hline Between groups & 1 & .272 & .272 & 1.143 & .292 \\
Withingroups & 37 & 8.805 & .238 & & \\
Total & 38 & 9.077 & & & \\
\hline
\end{tabular}

There was no significant difference found between the means of examination score and gender in this study, $F=.366, p=.549, p<.05$ (See Table 4.6).

Table 4-6

Difference benween examination score and gender

\begin{tabular}{lrrrrr}
\hline $\begin{array}{l}\text { Examination } \\
\text { Score }\end{array}$ & $d f$ & SS & MS & $F$ & $p$ \\
\hline Between groups & 1 & 52.370 & 52.370 & .366 & .549 \\
Withingroups & 37 & 5291.22 & 143.006 & & \\
Total & 38 & 5343.59 & & & \\
\hline
\end{tabular}

\subsection{Achievement goal factor inter-correlations}

The three achievement goal orientation factors used for this study were performance-approach, performance-avoidance, and mastery goal factors. Correlational analysis was performed on these three factors. The inter-correlation between mastery and performance-approach factors, related to hypothesis one, revealed a statistically significant result $(r=.322, \mathrm{p}<.05)($ See Table 4-7). 


\section{Table 4-7}

Achievement Goal Factor Inter-correlations

\begin{tabular}{llll}
\hline Irem & 1 & 2 & 3 \\
\hline 1. Performance-Approach & - & & \\
2. Performance-Avoidance & $-.046^{\mathrm{b}}$ & - & \\
3. Mastery & $.322^{\mathrm{a}}$ & $-.146^{\mathrm{b}}$ & - \\
\hline
\end{tabular}

Notes: ${ }^{a}$ comelation is significant at the .05 level (one-tailed): ${ }^{b}$ correlation is non-significant

\subsection{Achievement goal and study strategy factors}

The three achievement goal factors, identified as performance-approach, performance-avoidance, and mastery goals, were correlated with three study strategy factors: The study strategy factors that were used were deep-processing, surfaceprocessing, and disorganization. When achievement goal factors and study strategy factors were analyzed as correlations, five statistically significant correlations appeared.

Mastery goal factors and deep-processing study strategy factors, related to hypothesis two, were correlated and were statistically significant (See Table 4-8). 
Table 4-8

Factor Inter-correlations

\begin{tabular}{lcccccccc}
\hline Item & 1 & 2 & 3 & 4 & 5 & 6 & 7 & 8 \\
\hline 1. Performance-Approach & - & & & & & & \\
2. Performance-Avoidance & $-.046^{\mathrm{b}}$ & -- & & & & & \\
3. Mastery & $.322^{\mathrm{a}}$ & $-.146^{\mathrm{b}}$ & - & & & & \\
4. Deep-processing & $.384^{\mathrm{a}}$ & $-.029^{\mathrm{b}}$ & $.45^{\mathrm{a}}$ & - & & & & \\
5. Surface-processing & $.106^{\mathrm{b}}$ & $.386^{\mathrm{a}}$ & $.062^{\mathrm{b}}$ & $.069^{\mathrm{b}}$ & -- & & \\
6. Disorganization & $-.250^{\mathrm{b}}$ & $.341^{\mathrm{a}}$ & $-.239^{\mathrm{b}}$ & $-.210^{\mathrm{b}}$ & $.253^{\mathrm{b}}$ & -- & & \\
7. Persistence & $.177^{\mathrm{b}}$ & $-.208^{\mathrm{b}}$ & $.648^{\mathrm{a}}$ & $.332^{\mathrm{a}}$ & $.221^{\mathrm{b}}$ & $-.176^{\mathrm{b}}$ & - & \\
8. Examination score & $.112^{\mathrm{b}}$ & $-.326^{\mathrm{a}}$ & $.222^{\mathrm{b}}$ & $.228^{\mathrm{b}}$ & $-.160^{\mathrm{b}}$ & $-.384^{\mathrm{a}}$ & $.239^{\mathrm{b}}$ & - \\
\hline
\end{tabular}

Notes: ${ }^{9}$ correlation is significant at the .05 level (one-tailed); ${ }^{b}$ correlation is non-significant

The correlation between performance-approach goal factors and deep-processing study strategy factors, related to hypothesis three, was statistically significant (See Table 4-8). The performance-avoidance goal factors, related to hypothesis four, were statistically significant when correlated with surface-processing. Performance-avoidance goal factors, related to hypothesis five, were also significantly correlated with disorganization study strategy factors (See Table 4-8). In summary, the deep-processing study strategy factor was positively correlated with mastery as well as performanceapproach factors. Disorganization and surface-processing study strategy factors were positively correlated with performance-avoidance.

\subsection{Persistence}

Questions about persistence were included on the second questionnaire. The persistence factor was analyzed for correlations with achievement goal factors, and study strategy factors. The correlation between persistence and the mastery goal factor, related to hypothesis six, was statistically significant (See Table 4-8). The correlation between 
persistence and deep-processing study strategy factor, related to hypothesis seven, was statisticaliy significant (See Table 4-8). In summary, there was a statistically significant correlation between persistence and mastery, which is one of the achievement goal factors. When persistence was correlated with study strategy factors, deep-processing was statistically significant.

\subsection{Examination scores}

Examination scores were compared with achievement goal factors, study strategy factors, persistence, and age using correlational analyses. Descriptive statistics for examination score are shown in Table 4-9.

\section{Table 4-9}

Examimation Score Descriptite Statistics

\begin{tabular}{ccccc}
\hline & Minimum & Maximum & Mean & Standard Deviation \\
\hline Examination Score & 40 & 96 & 77.44 & 11.858 \\
\hline
\end{tabular}

There was a statistically significant and negative correlation between examination score and the performance-avoidance goal factor, as related to hypothesis eight (See Table 4-8). There was a negative and statistically significant correlation between examination score and the disorganization study strategy factor, as related to hypothesis nine (See Table 4-8). There was no statistically significant correlation between examination score and persistence (See Table 4-8). There was also no statistically significant correlation between examination score and age (See Table 4-10). 
Table 4-10

Correlation Between Examination

Score and Age

\begin{tabular}{lc}
\hline & Age \\
\hline Examination score & .048 \\
\hline
\end{tabular}

Note: correlation is non-significant

In sum, there was a statistically significant and negative correlation between examination score and the performance-avoidance achievement goal factor, consistent with hypothesis number eight. There was also a statistically significant and negative correlation between examination score and the disorganization study strategy factor, consistent with hypothesis number nine. Persistence and effort factors were shown to have no significant correlation to examination score. There was no significant correlation between examination score and participant age.

\subsection{Summary}

The primary purpose of this study was to examine if the hypothesized relationships between achievement goals, study strategies, and examination scores would persist with graduate students. To accomplish this purpose, the factors of achievement goals, student study strategies, persistence, and effort were correlated with each other for graduate students who were preparing for an examination. 


\section{Chapter Five}

\section{Conclusions and Recommendations for Future Research}

\subsection{Summary}

This study investigated potential variables that may be involved with retention of graduate students. The investigators hypothesized that student belief structures might have explanatory power for why graduate students seem to have difficulty being retained in school. Two theoretical constructs were under investigation in this study. The first construct was achievement goal theory, which seeks to explain a student's beliefs about the goals that are informing their decisions for learning. The second construct was an assessment of students' self-reported strategies for studying. While the correlations between an undergraduate student's achievement goals and study strategies are well documented, those correlations have not been fully examined with graduate students. As discussed in the literature review, achievement motivation was predictive of student achievement and student achievement was predictive of retention. A foundational question posed in this study was, if the factors identified in achievement motivation would operate in the same fashion as they did with the undergraduate population studied previously. Once again, using the correlation matrix in chapter four, the answer is yes. For ease of reference, the correlation matrix (Table 4-8) appearing in chapter four will be used again here. 
Table 4-8

Factor Inter-correlations

\begin{tabular}{lcccccccc}
\hline Item & 1 & 2 & 3 & 4 & 5 & 6 & 7 & 8 \\
\hline 1. Performance-Approach & - & & & & & & \\
2. Performance-Avoidance & $-.046^{\mathrm{b}}$ & -- & & & & & \\
3. Mastery & $.322^{\mathrm{a}}$ & $-.146^{\mathrm{b}}$ & - & & & & \\
4. Deep-processing & $.384^{\mathrm{a}}$ & $-.029^{\mathrm{b}}$ & $.415^{\mathrm{a}}$ & - & & & & \\
5. Surface-processing & $.106^{\mathrm{b}}$ & $.386^{\mathrm{a}}$ & $.062^{\mathrm{b}}$ & $.069^{\mathrm{b}}$ & - & & \\
6. Disorganization & $-.250^{\mathrm{b}}$ & $.341^{\mathrm{a}}$ & $-.239^{\mathrm{b}}$ & $-.210^{\mathrm{b}}$ & $.253^{\mathrm{b}}$ & - & & \\
7. Persistence & $.177^{\mathrm{b}}$ & $-.208^{\mathrm{b}}$ & $.648^{\mathrm{a}}$ & $.332^{\mathrm{a}}$ & $.221^{\mathrm{b}}$ & $-.176^{\mathrm{b}}$ & - & \\
8. Examination score & $.112^{\mathrm{b}}$ & $-.326^{\mathrm{a}}$ & $.222^{\mathrm{b}}$ & $.228^{\mathrm{b}}$ & $-.160^{\mathrm{b}}$ & $-.384^{\mathrm{z}}$ & $.239^{\mathrm{b}}$ & - \\
\hline
\end{tabular}

Notes: a correlation is significant at the .05 level (one-tailed); ${ }^{b}$ correlation is non-significant

As predicted, mastery and performance goal orientations were statistically correlated with each other. However, the relationship was weaker and statistically not significant for the correlation between mastery and performance-avoidance. As reported elsewhere, the relationships between these two sub-factors are not necessarily an inverse of each other. Zweig and Webster (2004) report that "the relationships between the mastery and performance constructs are oblique rather than orthogonal in nature," (pg 240) which could account for the lack of complete uniqueness in each construct. The literature performed with undergraduate students did find a statistically significant and negative correlation between mastery and performance-avoidance goal factors (Elliot, McGregor, and Gable, 1999). To help explain this apparent contrast, one might reasonably conjecture that those students who would otherwise choose performance-avoidance behaviors did not make it to graduate school to begin with and subsequently are not represented in the sample population investigated in this study. Secondarily, avoiding performance is no longer an option in graduate school and hence this factor (i.e., 
performance avoidance) may not be sensitive to that sort of measurement with graduate students. Stated alternatively, having a homogeneous population of essentially highachieving graduate students in the study population created the equivalent of a range restriction. The factor, performance-avoidance, probably remains a tenable construct; however, it only manifests itself as clearly as it does with less able students and less demanding examination circumstances. As a whole, the boundary conditions of achievement motivation seem to be holding, even in this high-demand environment with graduate students. In fact, each hypothesized relationship investigated in this study, whether statistical significance was achieved or not, paralleled previous findings with undergraduate students (Elliot, McGregor, \& Gable, 1999; Grant \& Dweck, 2003; Luo, Paris, Hogan, \& Luo, 2011).

\subsection{Achievement and study strategies}

The second family of questions had to do with the relationship between achievement motivation and study strategies (See Table 4.8). The proposed structure, and hypothesized relationships, of achievement motivation and study strategies were retained as predicted elsewhere in the literature. In fact, the effects were slightly larger than those found with undergraduate students. Of particular note, the correlation between the mastery construct and factors of persistence and deep processing had slightly larger effect sizes than found in some of the undergraduate literature (Elliot, McGregor, \& Gable, 1999; Wolters, 2004).

While these are not generally called such in the scholarly literature, it seems reasonable to characterize mastery orientations as a healthy adaptation to the demands of intellectual life. Similarly, one could think of high scores on the deep-processing study 
strategies as a construct representing a healthy adaptation. While all the constructs in this study exist on a continuum, it would seem reasonable to characterize students with high scores on performance avoidance and surface-level processing study strategies at a greater risk than their healthier counterparts. While the predictor variables in this study were not highly correlated with performance on that particular anatomy examination on that particular day, the fact remains that the constructs of achievement motivation and self-reported measures of study strategy are operationally relevant and may warrant further exploration.

\subsection{Conclusions}

The overall research agenda that the investigator pursued was to discover ways to help improve retention of graduate students. The entire picture of student retention was beyond the scope of this study. However, as discussed, achievement bas been a good proxy measure of what might eventually be an indication of retention. The question that the researcher attempted to answer for this study was if achievement motivation theory had sufficient explanatory power to explain performance on the most demanding examination in a single anatomy course. Determining if these constructs were predictive of retention will have to remain unanswered until the students in the study population are scheduled for graduation.

\subsection{Faculty can affect retention}

"It is one thing to know why students leave: it is another to know what institutions can to do help students stay and succeed" (Tinto, 2006, pg 6). However, there are more stakeholders in this process than just students. At a minimum, there are three sets of 
stakeholders associated with this project. These three include the individual student, the college professors vested in seeing that their students succeed in their studies, and the educational institutions. As discussed earlier, faculty may affect the type of achievement goal the student uses, which in turn, could affect the student's grade and his or her eventual retention or attrition (Ames, 1992; Svinicki, 1999). Researchers interpreting findings indicate that graduate student retention rates may be improved by keeping curriculum up to date as well as increasing faculty interaction with the students (Bain, Fedynich, \& Knight, 2010). Examples of ways that faculty can interact with students include "mentoring, advising, encouraging, coaching, and modeling" (pg 8). As it specifically relates to the current project, there are two points of entry to formulating instructional interventions. First, it is possible to find ways to encourage students to trade some of their less healthy achievement orientations for approaches to their studies that more resemble mastery orientations. Self-efficacy research and its accompanying literature make it abundantly clear what has to happen to help students embrace mastery orientations. Pajares (2002) outlines four sources of self-efficacy:

1. Mastery experience: This is the most influential source of efficacy information because it is based on authentic mastery experience. Successes raise efficacy appraisals; failures lower them. Once established, enhanced self-efficacy tends to generalize to other situations ... in activities that are similar to those in which self-efficacy was enhanced.

2. Vicarious experience: Although vicarious experiences are generally weaker than direct ones, vicarious forms can produce significant, enduring changes 
through their effects on performance. People convinced vicariously of their inefficacy are inclined to behave in ineffectual ways that, in fact, generate confirmatory behavioral evidence of inability. Conversely, modeling influences that enhance perceived self-efficacy can weaken the impact of direct experiences of failure by sustaining performances in the face of repeated failure. A given mode of influence can thus set in motion processes that augment its effects or diminish the effects of otherwise powerful influences.

3. Social persuasion (including verbal persuasions): Can contribute to successful performance if the heightened appraisal is within realistic bounds.

4. Physiological states: Treatments that eliminate emotional arousal to subjective threats heighten perceived self-efficacy with corresponding improvements in performance. (pg 568)

It does not require a great deal of educational imagination to know what sort of classroom contingencies could be put in place to achieve these ends.

\subsection{Promoting study strategies}

Promoting more effective study strategies is altogether more straightforward.

There is ample cognitive science literature to which university personnel could appeal to more directly teach students how to study well: Levels of Processing Theory (Craik \& Lockhart, 1972), Encoding Specificity Principle (Bransford, Brown, \& Cocking, 2004) and see especially, Prawat (1989). Actively intervening on student achievement orientations and study strategies is ultimately a matter of instructor and institutional resource commitment. 


\subsection{Recommendations for future research}

The examination used for the purposes of this study has a distinct local reputation at the University of St. Augustine as being extremely difficult. Going into this examination, students know of its reputation and attempt to prepare themselves accordingly. These students also receive a forty-five minute lecture on time management and study strategies in preparation for the second examination. This additional effort may lead to the students' achievement and study strategy perceptions as being very similar to each other and could therefore create a range restriction in the data. This restriction might lead to a type II error because graduate students are already a very homogenous group. A recommendation to help account for this potential problem is for researchers to replicate the study in course environments that are potentially less demanding with the same student population to see if effect sizes show up any larger, even in a modest way. This might also provide an opportunity to assess the longitudinal stability of the students' selfreport of goal and study strategy factors.

\subsection{Qualitative research component}

The investigators in this study used data that was strictly quantitative. At no time were the thoughts and feelings of the students included in the results of this study. This may be an important area to address because many strong feelings can be associated with success or failure in school. Including a qualitative component to the research design may help to garner additional clarification for where each graduate student resides on the achievement goal continuum. The qualitative component would consist of an interview with each student involved in the study. Investigators would direct questions toward the student's perception of his or her achievement goals as well as the strategies employed 
for studying. If future studies concerning achievement goal orientations, study strategies, and examination performance included a qualitative portion in the research design, they may provide additional nuances to the data that a quantitative design cannot reveal.

For interest sake, the instructor of the anatomy course did share his experience with students who have performed poorly on the second anatomy examination in the past. He states that students who performed poorly in the anatomy course demonstrate or admit four things. First, they never had to study as an undergraduate to get good grades. Second, they are having problems handling all the material for the depth needed. Third, they describe attributes or behaviors of passive learning. Lastly, they do not see the need to change their study habits.

\subsection{Instrumentation suggestion}

Researchers may direct future studies toward developing instruments that are specific to graduate students. Scholars developed the instruments used in this study specifically for the undergraduate student population. Graduate students are typically thought of as a more homogenous grouping of students than undergraduate students are. This may require a more tailored instrument specific to the field of study to discover the potentially small differences between each student. For example, instead of using a phrase like 'I am always challenging myself to learn new concepts' to measure for student perception of a mastery goal factor, it can be made more specific for those in a rehabilitation program and be stated, 'I am always challenging myself to learn new rehabilitation concepts.' 


\subsection{Repeated measures design}

It would be beneficial for the study as a whole to include multiple physical and occupational therapy school settings. However more importantly, and potentially easier to accomplish, would be a repeated measures design where the same subjects act as their own control. As mentioned above, it would be to do this same study again under a less rigorous examination situation. In addition, it would be helpful to look at how the students' perceptions of achievement goals and study strategies change over time as the students move through the program.

\subsection{Conclusion}

Professional graduate student programs have relatively low completion rates, which comes at significant cost to the university and student alike. Achievement goal orientation can account for success or failure with undergraduate students, but has not been fully tested with graduate students. This study found that there was a relationship between a graduate student's achievement goal orientation and examination performance, as well as a graduate student's achievement goal orientation and type of study strategy use in first-term graduate students at the University of St. Augustine. Certain achievement goal orientations and study strategy combinations may affect a student's academic success. Achievement goal orientations, along with study strategies may be helpful criteria to identify students most likely to succeed in graduate programs. 


\section{References}

American College Testing Organization. (2011). Institutional Data File. Retrieved 7/9/2012 from http://www.act.org/research/policymakers/pdf/retain_2011.pdf

American College Testing Organization. (2006). Institutional Data File. Retrieved 7/9/2012 from http://www.act.org/research/policymakers/pdf/retain_2006.pdf

American College Testing Organization. (2000). Institutional Data File. Retrieved 7/9/2012 from http://www.act.org/research/policymakers/pdf/retain_2000.pdf

American Physical Therapy Association. (2012). A model to project the supply and demand of physical therapists 2010 - 2020. APTA Workforce Data. Retrieved 9/8/12 from www.apta.org/WorkforceData/ModelDescriptionFigures/

Amies, C. (1992). Classrooms: Goals, structures, and student motivation. Journal of Educational Psychology, 84(3), 261-271.

Ames, C., \& Archer, J. (1988). Achievement goals in the classroom: Students' learning strategies and motivation processes. Journal of Educational Psychology, 80, 260-267.

Andrews, A. W., Johansson, C., Chinworth, S. A., \& Akroyd, D. (2006). Cognitive, collegiate, and demographic predictors of attrition in professional physical therapist education. Journal of Physical Therapy Education, 20(1), 14-21.

Atkinson, J. W. (1958). Motives in fantasy, action, and society: $A$ method of assessment and study. Princeton, NJ: Van Nostrand.

Atkinson, J. W. (1964). An introduction to motivation. New York, NY: Van Nostrand.

Atkinson, J. W., \& Feather, N. T. (Eds.). (1966). A theory of achievement motivation. New York, NY: Wiley.

Atkinson, J. W., \& Raynor, J. O. (1974). Motivation and achievement. New York, NY: Wiley. 
Bain, S., Fedynich, L. V., \& Knight, M. (2010). The successful graduate student: A review of the factors for success. Journal of Academic and Business Ethics. Retrieved from http://www.aabri.com/manuscripts/10569.pdf

Baird, L. L. (1993). Increasing graduate student retention and degree attainment: Using research and theoretical models of graduate student progress. New Directions for Institutional Research, 15(4), 3-12.

Bandura, A. (1975). Social learning \& personality development. Holt, Rinehart \& Winston, INC: NJ.

Bandura, A. (1986). Social foundations of thought and action: A social cognitive theory. Englewood Cliffs, NJ: Prentice Hall.

Bandura, A. (1997). Self efficacy: The exercise of control. New York: Freeman

Barron, K. E., \& Harackiewicz, J. M. (2001). Achievement goals and optimal motivation:

Testing multiple goal models. Journal of Personality and Social Psychology, 80(5), 706722. doi: $10.1037 / / 0022-3514.80 .5 .706$

Bransford, J. D., Brown, A. L., Cocking, R. R. (2004). How people learn: Brain, mind, experience, and school. Washington, D.C.: National Academy Press.

Broekkamp, H., \& Van Hout-Wolters, B. H. A. M. (2007). Students' adaptation of study strategies when preparing for classroom tests. Educational Psychological Review, 19, 401-428. doi: $10.1007 / \mathrm{s} 10648-006-9025-0$

Brophy, J. (1999). Toward a model of the value aspects of motivation in education: Developing appreciation for particular learning domains and activities. Educational Psychologist, 34, 75-85.

Button, S. B., Mathieu, J. E., \& Zajac, D. M. (1996). Goal orientation in organizational research: A conceptual and empirical foundation. Organizational Behavior and Human Decision Processes, 67(1), 26-48.

Chatterjee, S., \& Ionescu, F. (2012). Insuring student loans against the financial risk of college failure. Federal Reserve Bank of Philadelphia. Retrieved from 
http://www.philadelphiafed.org/research-and-data/publications/workingpapers/2012/wp12-15.pdf

Conley, A. M. (2012). Patterns of motivation beliefs: Combining achievement goal and expectancy-value perspectives. Journal of Educational Psychology, 104(1), 32-47. doi: $10.1037 / \mathrm{a} 0026042$

Council of Graduate Schools. (2012). Attrition and completion. Retrieved from: http://www.cgsnet.org/attrition-and-completion

Covington, M. V. (1999). Caring about learning: The nature and nurturing of subject-matter appreciation. Educational Psychologist, 34(2), 127-136.

Covington, M. V. (2000). Goal theory, motivation, and school achievement: An integrative review. Annual Review of Psychology, 51, 171-200.

Covington, M. V., \& Omelich, C. L. (1991). Need achievement revisited: Verification of Atkinson's original 2 x 2 model. In C. D. Spielberger, I. G. Sarason, Z. Kulcsar, \& G. L. Van Heck (Eds.), Stress and emotion, Vol. 14. New York, NY: Hemisphere.

Craik, F. I. M., \& Lockhart, R. S. (1972). Levels of processing: A framework for memory research. Journal of Verbal Learning and Verbal Behavior, 11, 671-684.

Crede, M., \& Kuncel, N. R. (2008). Study habits, skills, and attitudes: The third pillar supporting coiliegiate academic performance. Ferspectives on Psychologicai Science, 3(6), 425-453. doi: $10.1111 / \mathrm{j} .1745-6924.2008 .00089$

Davidson, W. B., Beck, H. P., \& Milligan, M. (2009). The college persistence questionnaire: Development and validation of an instrument that predicts student attrition. Journal of College Student Development, 50(4), 373-390.

Diener, C. I., \& Dweck, C. S. (1980). An analysis of learned helplessness: II. The processing of success. Journal of Personality and Social Psychology, 39(5), 940-952.

Duda, J., \& Nicholls, J. (1992). Dimensions of achievement motivation in schoolwork and sport. Journal of Educational Psychology, 84, 290-299. 
Dupeyrat, C., Mariné, C. (2005). Implicit theories of intelligence, goal orientation, cognitive engagement, and achievement: A test of Dweck's model with returning to school adults. Contemporary Educational Psychology, 30, 43-59. doi: 10.1016/j.cedpsych.2004.01.007

Dweck, C. S., \& Elliot, E. S. (1983). Achievement motivation. In P. Mussen \& E. M. Hetherington (Eds.), Handbook of child psychology (pp. 643-691). New York: Wiley.

Dweck, C. S. (1986). Motivational processes affecting learning. American Psychologist, 41(10), 1040-1048.

Dweck, C. S., \& Leggett, E. L. (1988). A social-cognitive approach to motivation and personality. Psychological Review, 95, 256-273.

Dweck, C. S., \& Reppucci, N. D. (1973). Learned helplessness and reinforcement responsibility in children. Journal of Personality and Social Psychology, 25(1), 109-116.

Elliot, A. J., \& Church, M. A. (1997). A hierarchical model of approach and avoidance achievement motivation. Journal of Personality and Social Psychology, 72(1), 218-232.

Elliot, A. J., \& Harackiewicz, J. M. (1996). Approach and avoidance achievement goals and intrinsic motivation: A mediational analysis. Journal of Personality and Social Psychology, 70, 461-475, doi: 10.1037/0022-3514.70.3.461

Elliot, A. I., \& McGregor, H. A. (2001). A $2 \times 2$ achievement goal framework. Journal of Personality and Social Psychology, 80(3), 501-519.

Elliot, A. J., McGregor, H. A., \& Gable, S. (1999). Achievement goals, study strategies, and exam performance: A mediational analysis. Journal of Educational Psychology, 91(3), 549-563. doi: 10.1037//0022-3514.80.3.501

Elliott, E. S., \& Dweck, C. S. (1988). Goals: An approach to motivation and achievement. Journal of Personality and Social Psychology, 54, 5-12.

Fenollar, P., Román, S., \& Cuestas, P. J. (2007). University students' academic performance: An integrative conceptual framework and empirical analysis. British Journal of Educational Psychology, 77(4), 873. 
Freud, S. (1966). The complete introductory lectures on psychoanalysis (J. Starchey, Trans.). New York: Norton.

Gardner, S. K. (2008). Fitting the mold of graduate school: A qualitative study of socialization in doctoral education. Innovative Higher Education, 33, 125-138. Retrieved from www. umaine.edu/edhd/files/2010/02/Gardner-Fitting-the-Mold.pdf

Gardner, S. K. (2009). Student and faculty attributions of attrition in high and low-completing doctoral programs in the United States. Higher Education, 58, 97-112. doi: $10.1007 / \mathrm{s} 10734-008-9184-7$

Gettinger, M., \& Seibert, J. K. (2002). Contributions of study skills to academic competence. School Psychological Review, 31(3), 350-365.

Girves, J. E., \& Wemmerus, V. (1988). Developing models of graduate student degree progress. The Journal of Higher Education, 59(2), 163-189.

Golde, C. M. (2005). The role of the department and discipline in doctoral student attrition: Lessons from four departments. The Journal of Higher Education, 76(6), 669-700.

Graham, S., \& Weiner, B. (1996). Cognition and Motivation: Theories and Principles of Motivation. Retrieved from www.unco.edu/cebs/psychology/...'graham_weiner96.pdf

Graham, S., Weiner, B. (1996). Theories and Principles of Motivation. In Handbook of Educational Psychology, ed. David C. Berliner and Robert C. Calfee. New York: Macmillan.

Grant, H., \& Dweck, C. S. (2003). Clarifying achievement goals and their impact. Journal of Personality and Social Psychology, 85(3), 541-553. doi: 10.1037/0022-3514.85.3.541

Handelsman, M. M., \& Briggs, W. L., Sullivan, N, Towler, A. (2005). A measure of college student course engagement. The Journal of Educational Research, 98(3), 184.

Harackiewicz, J. M., Barron, K. E., Pintrich, P. R., Elliot, A. J., \& Thrash, T. M. (2002). Revision of achievement goal theory: Necessary and illuminating. Journal of Educational Psychology, 94(3), 638-645. doi: 10.1037//0022-0663.94.3.638 
Harackiewicz, J. M., Barron, K. E., Tauer, J. M., Carter, S. M., \& Elliot, A. J., (2000). Shortterm and long-term consequences of achievement goals: Predicting interest and performance over time. Journal of Educational Psychology, 92(2), 316-330. doi: 10.1037//0022-0663.92.2.316

Harakiewicz, J. M., Barron, K. E., Tauer, J. M., Elliot, A. J. (2002). Predicting success in college: A longitudinal study of achievement goals and ability measures as predictors of interest and performance from freshman year through graduation. Journal of Educational Psychology, 94(3), 562-575. doi: 10.1037//0022-0663.94.3.562

Harackiewicz, J. M., Rozek, C. S., Hulleman, C. S., \& Hyde, J. S. (2012). Helping parents to motivate adolescents in mathematics and science: An experimental test of utility-value intervention. Psychological Science, 23(8), 899-906. doi: 10.1177/0956797611435530

Huang, C. (2012). Discriminant and criterion-related validity of achievement goals in predicting academic achievement: A meta-analysis. Journal of Educational Psychology, 104(1), 4873. doi: $10.1037 / \mathrm{a} 0026223$

Hull, C. L. (1943). Principles of behavior: An introduction to behavior theory. New York: Appleton-Century-Crofts.

Isaac, P. D. (1993). Measuring graduate student retention. New Directions for Institutional Research, 80, 13-25. Jossey-Bass.

Jones, B. D., Wilkins, J. L. M., Long, M. H., \& Wang, F. (2012). Testing a motivational model of achievement: How students' mathematical beliefs and interests are related to their achievement. European Journal of Psychology of Education, 27, 1-20. doi: $10.1007 / \mathrm{s} 10212-011-0062-9$

Jones, L. R. (2002). A look at girls' attitudes toward math, science, and technology. Are we really making a difference? Virginia Society for Technology in Education, 16(3), 3-7.

Lewin, K. (1935). A dynamic theory of personality: Selected papers (D. K. Adams \& K. E. Zener, Trans.). New York: McGraw-Hill.

Lotkowski, V. A., Robbins, S. B., Noeth, R. J. (2004). The role of academic and non-academic factors in improving college retention: ACT policy report. American College Testing Organization. Retreived from www.act.org/research/policy/index.html 
Lovitts, B. E. (2001). Leaving the Ivory Tower: The Causes and Consequences of Deporture from Doctoral Study. Lanham, MD: Rowman and Littlefield Publishers, Inc.

Luo, W., Paris, S. G., Hogan, D., \& Luo, Z. (2011). Do performance goals promote learning? A pattern analysis of Singapore students' achievement goals. Contemporary Educational Psychology, 36, 165 176. doi: 10.1016/j.cedpsych.2011.02.003

Mattern, R. A. (2005). College students' goal orientations and achievement. International Journal of Teaching and Learning in Higher Education, 17(1), 27-32.

Murayama, K., Elliot, A. J., \& Yamagata, S. (2011). Separation of performance-approach and performance-avoidance achievement goals: A broader analysis. Journal of Educational Psychology, 103(1), 238-256. doi: 10.1037/a0021948

Nicholls, J. G. (1975). Causal attributions and other achievement-related cognitions: Effects of task outcome, attainment value, and sex. Journal of Personality and Social Psychology, $31(3), 379-389$.

Nolen, S. B. (1987). The hows and whys of studying: The relationship of goals to strategies. Paper presented at the Annual Meeting of the American Educational Research Association, Washington, DC.

Pajares, F. (2002). Self-efficacy beliefs in academic contexts: An outline. Retreived November, 30,2012 , from hitp://dies.emory.edu/mfp/effitalk.html.

Pajares, F. (2002). Overview of social cognitive theory and of self-efficacy. Retrieved November, 30,2012 from http://www.uky.edu/ eushe2/Pajares/eff.html

Phan, H. P. (2009). The reciprocality between critical thinking and deep processing strategies: A longitudinal approach. Conference paper for the AARE, 2009, Canberra Australia.

Pintrich, P. R. (2000). An achievement goal theory perspective on issues in motivation terminology, theory, and research. Contemporary Educational Psychology, 25, 92-104. doi: $10.1006 /$ ceps. 1999.1017

Pintrich, P. R. (2003). A motivational science perspective on the role of student motivation in learning and teaching contexts. Journal of Educational Psychology, 95, 667-686. 
Pontius, J. L., \& Harper, S. R. (2006). Principles for good practice in graduate and professional student engagement. New Directions For Student Services, 115, 47-58. doi: $10.1002 /$ ss. 215

Prawat, R. S. (1989). Promoting access to knowledge, strategy, and disposition in students: A research synthesis. Review of Educational Research, 59(1), 1-41.

Ramist, L. (1981). College student attrition and retention. College Board Report, 81(1), 1-37.

Read, J. (2000). Correlation or regression? University of Leicester. Retrieved from: http://www.le.ac.uk/b1/gat/virtualfc/Stats/regression/regrcorr.html

Robbins, S. B., Lauver, K., Le, H., Davis, D., Langley, R., \& Carlstrom, A. (2004). Do psychosocial and study skill factors predict college outcomes? A meta-analysis. Psychological Bulletin, 130(2), 261-288, doi: 10.1037/0033-2909.130.2.261

Roeser, R. W., Midgley, C., \& Urdan, T. C. (1996). Perceptions of the school psychological and early adolescents' psychological and behavioral functioning in school: The mediating role of goals and belonging. Journal of Educational Psychology, 88(3), 408-422.

Rotter, J. B. (1966). Generalized expectancies for internal versus external control of reinforcement. Psychological Monographs, 80 (Whole No. 609).

Rotter, J. B. (1990). Internal versus external control of reinforcement: A case history of a variable. American Psychologist, 45(4), 489-493.

Rummel, A., Action, D., Costello, S., \& Pielow, G. (1999). Is all retention good? An empirical study. College Student Journal, 33(2), Retrieved from http://www.freepatentsonline.com/article/College-Student-Journal/62839424.html

Schunk, D. H. (1996). Goal and self-evaluative influences during children's cognitive skill learning. American Educational Research Journal, 33, 359-382.

Schunk, D. H., Pajares, F., Wigfield, A., Eccles, J. S. (2002). Development of achievement motivation. A volume in the educational psychology series; 15-31, San Diego, CA: U.S. Academic Press, xvii, 366. doi: 10.1016/b978-012750053-9/50003-6 
Schunk, D. H., Pintrich, P. R., \& Meece, J. (2008). Motivation in education: Theory, research and applications (3rd ed.). Upper Saddle River, NJ: Pearson.

Senko, C., Hulleman, C. S., \& Harackiewicz, J. M. (2011). Achievement goal theory at the crossroads: Old controversies, current challenges, and new directions. Educational Psychologist, 46(1), 26-47, doi: 10.1080/00461520.2011.538646

Senko, C., \& Miles, K. M. (2008). Pursuing their own learning agenda: How mastery-oriented students jeopardize their class performance. Contemporary Educational Psychology, 33, 561-583. doi: 10.1016/j.cedpsych.2007.12.001

Simons, J., Dewitte, S., \& Lens, W. (2004). The role of different types of instrumentality in motivation, study strategies, and performance: Know why you learn, so you'll know what you learn. British Journal of Educational Psychology, 74, 343-360

Sizoo, S. L., Agrusa, J. F., \& Iskat, W. (2005). Measuring and developing the learning strategies of adult career and vocational education students. Education, I25(4), 527-538.

Skinner, B. F. (1953). Science and human behavior. New York: Free Press.

Smallwood, S. (2004, January 16). Doctor dropout. The Chronicle of Higher Education, 19 A. Retrieved from http://chronicle.com/article/Doctor-Dropout/33786/

Solomon, H. H. (2000). Students' evaluation of the effectiveness of academic advisors in the college of family life at Utah State University. (Unpublished master's thesis). Utah State University, Logan.

SPSS Inc. (2009). PASW Statistics GradPack18.0. Chicago.

Svinicki, M. D. (1999). New directions in learning and motivation. New Directions for Teaching and Learning, 80, 5-27.

Tinto, V. (1997). Classrooms as communities: Exploring the educational character of student persistence. Journal of Higher Education, 68, 599-623.

Tinto, V. (2006). Research and practice of student retention: What next? Journal of college student retention, 8(1), 1-19. 
University of St. Augustine for Health Sciences. (2012). Graduation statistic report.

U.S. Department of Education. (2011). Default rates rise for federal student loans. Retrieved 11/25/12 from http://www.ed.gov/news/press-releases/default-rates-rise-federal-studentloans

VandeWalle, D. (1997). Development and validation of a work domain goal orientation instrument. Educational and Psychological Measurement, 57, 995-1015. doi:10.1177/0013164497057006009

Weiner, B. (1992). Human motivation: Mietophors, theories, and research. Newbury Park, CA: Sage.

White, R. W. (1959). Motivation reconsidered: The concept of competence. Psychological Review, 66(5), 297-333. doi: 10.1037/h0040934

Wigfield, A. \& Eccles, J. S. (1992). The development of achievement task values: A theoretical analysis. Developmental Review, 12, 265-310.

Wigfield, A. (1994). Expectancy-value theory of achievement motivation: A developmental perspective. Educational Psychology Review, 6(1), 49-78.

Wolters, C. A. (2004). Advancing achievement goal theory: Using goal structures and goal orientations to predict students' motivation, cognition, and achievement. Journal of Educational Psychology, 96(2), 236-250. doi: 10.1037/0022-0663.96.2.236

Woodworth, R. S. (1918). Dynamic psychology. New York: Colombia University Press.

Zeyl, D. J. (1980). Socrates and hedonism: "Protagoras" 351b-358d. Phronesis, 25(3), 250-269. Retrieved from http://www.jstor.org/stable/4182098

Zweig, D., \& Webster, J. (2004). Validation of a multidimensional measure of goal orientation. Canadian Journal of Behavioural Science, 36(3), 232-243. 


\section{Appendix A}

Questionnaire \#1: To be completed prior to the exam

Age:_ Gender: M/F Degree: PT / OT Birth month:

Fill in the bubble on the scan-tron card that most appropriately reflects yourself along the continuum from $\mathrm{A}=$ Not at all true of $\mathrm{me}$, to $\mathrm{E}=$ Very true of me. Thank you for your time.

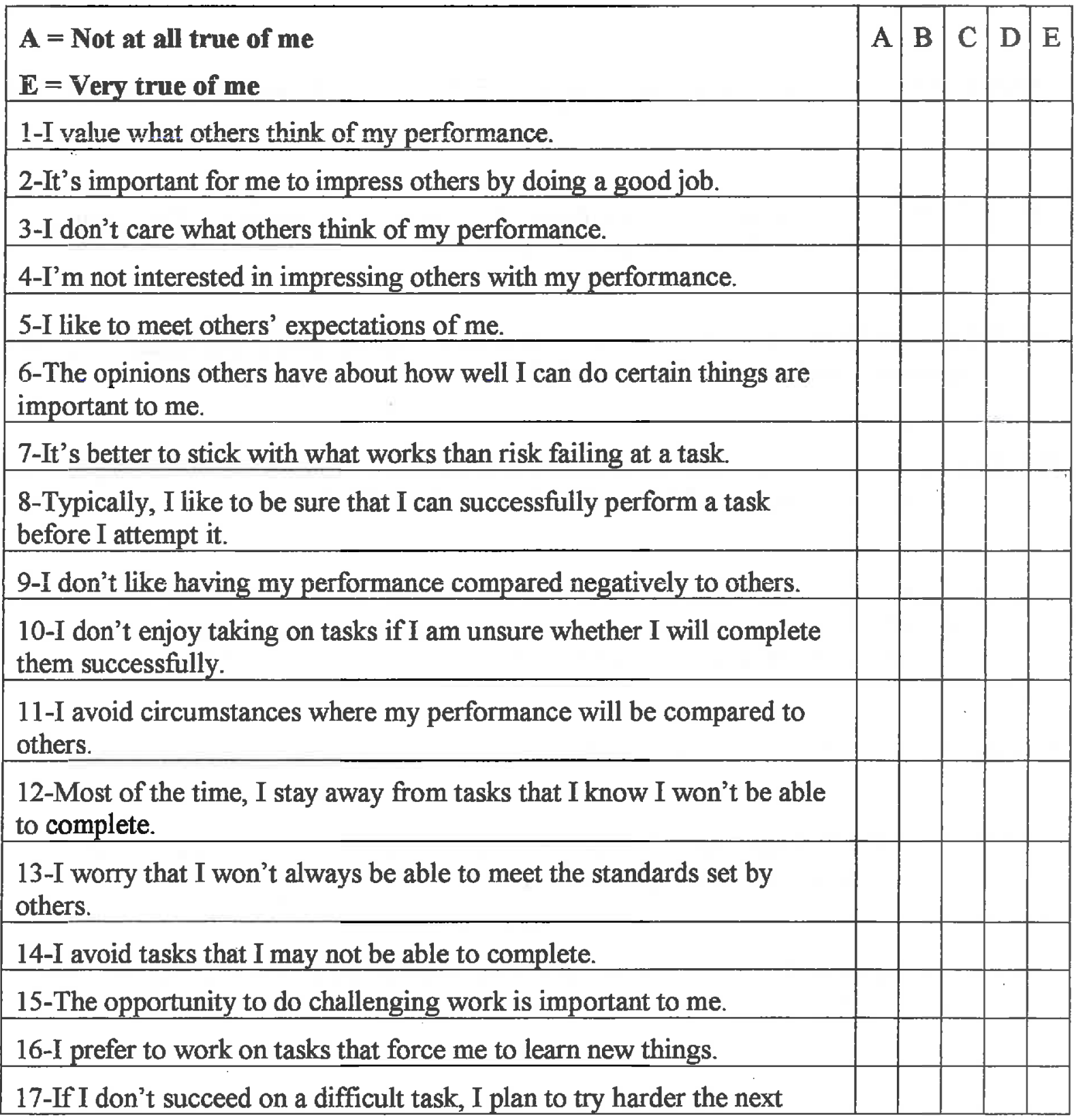


time.

18-In learning situations, I tend to set fairly challenging goais for myself.

19-I am always challenging myself to learn new concepts.

20-The opportunity to extend my range of abilities is important to me.

21-The opportunity to learn new things is important to me. 


\section{Appendix B}

\section{Questionnaire \#2: To be completed prior to the exam}

Age:

Gender: $\mathrm{M} / \mathrm{F}$

Degree: PT / OT

Birth month:

Fill in the bubble on the scan-tron card that most appropriately reflects yourself along the continuum from $A=$ Not at all true of me, to $E=$ Very true of me. Thank you for your time.

\begin{tabular}{|c|c|c|c|c|c|}
\hline $\begin{array}{l}A=\text { Not at all true of me } \\
E=\text { Very true of me }\end{array}$ & A & B & $\mathrm{C}$ & $\mathbf{D}$ & $\mathrm{E}$ \\
\hline $\begin{array}{l}\text { 1-When a theoretical point or conclusion is presented in lecture or in } \\
\text { the text, I try to decide if there is good supporting evidence. }\end{array}$ & & & & & \\
\hline $\begin{array}{l}\text { 2-I treat the course material as a starting point and try to develop my } \\
\text { own ideas about it. }\end{array}$ & & & & & \\
\hline $\begin{array}{l}\text { 3-Whenever I read or hear a theoretical point in this course, I think } \\
\text { about possible alternatives. }\end{array}$ & & & & & \\
\hline $\begin{array}{l}\text { 4-I never question the validity of the theories presented in the text or } \\
\text { by the professor. }\end{array}$ & & & & & \\
\hline $\begin{array}{l}\text { 5-I try to think through topics and decide what I am supposed to learn } \\
\text { from them, rather than studying topics by just reading them over. }\end{array}$ & & & & & \\
\hline $\begin{array}{l}\text { 6-When I study for the exam, I try to memorize as many facts as I } \\
\text { can. }\end{array}$ & & & & & \\
\hline $\begin{array}{l}\text { 7-When I study for this course, I go through the text and my lecture } \\
\text { notes and try to find the most important ideas to memorize. }\end{array}$ & & & & & \\
\hline $\begin{array}{l}\text { 8-When studying for this course, I read the text and my notes over } \\
\text { and over again to help me remember the material. }\end{array}$ & & & & & \\
\hline $\begin{array}{l}\text { 9-I study for this course by memorizing the definitions at the end of } \\
\text { each chapter of the text. }\end{array}$ & & & & & \\
\hline 10-I try to memorize everything that I think will be on the exam. & & & & & \\
\hline 11-I am not sure how to study for this course. & & & & & \\
\hline 12-I often find that I don't know what to study or where to start. & & & & & \\
\hline 13-I find it difficult to develop a study plan for this course. & & & & & \\
\hline 14-I find it difficult to organize my study time effectively. & & & & & \\
\hline $\begin{array}{l}\text { 15-When I study for this course, I have trouble figuring out what to } \\
\text { do to learn the material. }\end{array}$ & & & & & \\
\hline
\end{tabular}


16-When I become confused about something I'm reading for this course, I go back and try to figure it out.

17-Regardless of whether or not I like the material, I work my hardest to learn it.

18-When something that I am studying gets difficult, I spend extra time and effort trying to understand it.

19-I try to learn all of the testable material "inside and out", even if it is boring. 


\section{Appendix C}

Questionnaire \#3: To be administered after completing the exam
Age:
Gender: $\mathrm{M} / \mathrm{F}$
Degree: PT / OT
Birth month:

Fill in the bubble on the scan-tron card that most appropriately reflects yourself along the continuum from $A=$ Not at all true of $m e$, to $E=$ Very true of me. Thank you for your time.

\begin{tabular}{|l|l|l|l|l|l|}
\hline $\begin{array}{l}\mathbf{A}=\text { Not at all true of me } \\
\mathbf{E}=\text { Very true of me }\end{array}$ & A & B & C & D & E \\
\hline 1-I put a lot of effort into preparing for the exam. & & & & \\
\hline 2-I worked very hard to prepare for the exam. & & & & \\
\hline
\end{tabular}

